Division of

Gastroenterology,

University Hospital,

Nottingham, UK

J Jones

Literature review and document preparation for the working party was done by

J Jones. Members of the

working party are given below

and detailed in the appendix.

Letchworth, Herts

SG6 1DG, UK

J Boorman

Cleveland General

Hospital,

Middlesborough,

Cleveland, UK

P Cann

St Mark's Hospital, Northwick Park, UK A Forbes

Digestive Diseases

Research Centre, St

Bartholomew's

Hospital, London, UK

J Gomborone

Department of

Medicine, University of

Bristol, Bristol, UK

K Heaton

Centre for Health

Studies, University of

Durham, Durham, UK

P Hungin

St George's Hospital,

Tooting, London, UK

D Kumar

Department of

Gastroenterology and

Psychological

Medicine, St

Bartholomew's

Hospital, London, UK

G Libby

Division of

Gastroenterology,

University Hospital,

Queen's Medical

Centre, Nottingham,

UK

R Spiller

Department of Human

Physiology and

Nutrition, University of

Sheffield, Northern

General Hospital,

Sheffield, UK

N Read

Department of

Gastroenterology and

Nutrition, Central

Middlesex Hospital,

London, UK

D Silk

Department of

Medicine, Withington

Hospital, University

Hospital of South

Manchester, UK

P Whorwell

Correspondence to:

Dr R Spiller, Division of

Gastroenterology, C Floor,

South Block,

South Block, University

NG7 2UH, UK. Email: Robin.Spiller@nottingham.ac.uk initial document was further developed after a

\subsection{Preface}

1.1 PURPOSE OF GUIDELINES

These guidelines were compiled by a multidisciplinary group at the request of the chairman of the British Society of Gastroenterology's Clinical Services Committee. The prime targets for these guidelines are consultant gastroenterologists, specialist registrars in training, and general practitioners. The purpose is to identify and inform the key decisions to be made in the management of patients thought to have functional diseases of the gut. As these comprise the commonest conditions seen by gastroenterologists, the working party represented a wide spectrum of practitioners in gastroenterology, including gastroenterologists from both district general hospitals and tertiary referral centres, as well as primary care practitioners, psychiatrists, psychologists, and dietitians.

\subsection{SPECIFIC DIFFICULTIES}

Compared with producing guidelines for the management of well defined diseases such as peptic ulcer where there is a clear disease entity, an obvious end point, and highly effective treatments, drawing up guidelines for functional gastroenterological disorders has had many difficulties. Clinical trials have been difficult to design as the conditions being treated are highly variable with many possible end points, and most therapies only marginally more effective than placebo. Early trials were difficult to evaluate because of inadequate patient definition so that many questions have yet to be addressed with good quality randomised controlled clinical trials. Most of our recommendations are therefore supported by clinical experience rather than randomised controlled clinical trials. Finally, because functional diseases, although potentially debilitating, are non-fatal there are few uniformly available audit measures such as mortality or survival times by which to judge or compare different treatment regimens in different areas of clinical practice.

\subsection{PROCESS OF GUIDELINE CREATION}

The co-chairmen were approached by the chairman of the British Society of Gastroenterology's Clinical Services Committee and invited to form a working party. Members were chosen to be broadly representative of clinicians and academics with a long term interest and publication record in the field of functional bowel disease. A preliminary document was produced and subsequently modified during several meetings of the working party. The

\title{
British Society of Gastroenterology guidelines for the management of the irritable bowel syndrome
}

\author{
J Jones, J Boorman, P Cann, A Forbes, J Gomborone, K Heaton, P Hungin, D Kumar, \\ G Libby, R Spiller, N Read, D Silk, P Whorwell
}

comprehensive literature search by Dr J Jones, specialist registrar in the Department of Gastroenterology, University Hospital Nottingham. This involved a review of personal and electronic databases including Medline, PubMed and Ovid using keywords such as "functional disease", "dyspepsia", "irritable bowel syndrome", "spastic colon", and "irritable colon". Further information was obtained from references in quoted papers and by contacting relevant pharmaceutical companies, and a total of 2521 relevant papers were identified. This preliminary document was modified after several reviews by members of the working party and submitted to the Clinical Services Committee for independent review. Members of the British Society of Gastroenterology Council then further reviewed the document. Comments from these reviewers and representatives of the IBS patient group, the IBS network, have been incorporated into the final version

1.4 CATEGORIES OF EVIDENCE

The strength of evidence used in the formulation of these guidelines was graded according to the following system, which has been used in previous British Society of Gastroenterology (BSG) guidelines. However, in the context of functional diseases it should be recognised that this tends to over value the contribution of randomised, double blind, placebo controlled trials at the expense of studies of psychological treatments, which are difficult or impossible to double blind.

Grade Ia: evidence obtained from metaanalysis of randomised, double blind, placebo controlled trials.

Grade Ib: evidence obtained from at least one randomised, double blind, placebo controlled trial.

Grade IIa: evidence obtained from at least one well designed placebo controlled study without randomisation.

Grade IIb: evidence obtained from at least one other type of well designed quasiexperimental study.

Grade III: evidence obtained from well designed non-experimental descriptive studies such as comparative studies, correlation studies, and case studies.

Abbreviations used in this paper: BSG, British Society of Gastroenterology; IBS, irritable bowel syndrome; GI, gastrointestinal; FGD, functional gastrointestinal disorders; FD, functional dyspepsia; FBC, full blood count; ESR, erythrocyte sedimentation rate; $\mathrm{CBT}$, cognitive behavioural therapy; ACC, anterior cingulate cortex. 
Grade IV: evidence obtained from expert committee reports or opinions, clinical experiences, or respected authorities.

1.5 GRADING OF RECOMMENDATIONS

The strength of each recommendation depends on the category of the evidence supporting it, and is graded according to the following system:

Grade A: requires at least one randomised controlled trial as part of the body of literature of overall good quality and consistency (evidence categories Ia, $\mathrm{Ib})$.

Grade B: requires the availability of clinical studies without randomisation (evidence categories IIa, IIb, III).

Grade C: requires evidence from expert committee reports or opinions, or clinical experience of respected authorities, in the absence of directly applicable clinical studies of good quality (evidence category IV).

1.6 SCHEDULED REVIEW OF GUIDELINES

It is proposed that these guidelines be presented on the BSG world wide web page and be available for comment. They should be reviewed at 2-3 year intervals taking into account feedback from both public and profession, as well as new scientific evidence. Comments on these guidelines should be sent to Dr R C Spiller or Dr A Forbes.

\subsection{SUMMARY OF AUDIT GOALS}

Audit of the management of non-fatal conditions requires assessment of somewhat subjective quality of life parameters rather than the familiar morbidity and mortality statistics. Ideally patients with functional gastrointestinal disease would have a diagnosis established with the minimum of investigations without missing significant alternative diagnoses. They would then enter a treatment programme with high efficacy which reduced the need for further consultations and procedures. Specific audit goals might include:

- Achieving an acceptably low proportion of missed non-functional diagnoses during one year of follow up, which would be lower for serious diagnoses such as cancer $(<1 \%)$ while for less serious diagnoses such as lactose intolerance $<10 \%$ might be acceptable.

- Ensuring a minimum number of patients aged $<45$ years undergo negative barium studies during diagnostic work up.

- Reducing the number of work days missed through ill health after functional diagnosis made compared with before diagnosis.

- Reducing the frequency of physician visits for both gastrointestinal (GI) and non-GI related complaints after diagnosis and treatment.

- Improving quality of life after consultation, investigation, and management.

\subsection{Summary}

2.1 OVERVIEW

Functional gastrointestinal disorders (FGD) are the result of disordered GI function in the absence of known pathology of structure. FGD are among the commonest medical conditions; functional dyspepsia (FD) and irritable bowel syndrome (IBS) account for $40-60 \%$ of referrals to gastroenterology outpatient clinics.

2.2 FOCUS OF THIS REPORT

The specific recommendations which follow refer to IBS but because of extensive overlap, much of the general recommendations also apply to other functional disorders including non-ulcer dyspepsia and non-cardiac chest pain. However, to avoid lack of focus in this report, specific recommendations for these latter conditions will be addressed in separate guidelines.

\subsection{DIFFERENCES BETWEEN PRIMARY AND}

SECONDARY CARE

Most published studies of IBS are from academic units describing referred patients who differ significantly from those seen in general practice, being less likely to accept a psychological explanation of their symptoms and more convinced they have organic disease.

2.4 EPIDEMIOLOGY

IBS is common, affecting $9-12 \%$ of the population with a female/male ratio ranging from 1.1 to 2.6 depending on the weight given to individual symptoms. Age and race have no consistent effect on incidence of symptoms.

\subsection{AETIOLOGY}

Psychological morbidity. Most cases seen in general practice do not have major psychological morbidity. However, those who progress to outpatients have a higher incidence of psychological symptoms and psychiatric disease.

Role of stress. Studies of hospital outpatients suggest that approximately $50 \%$ attribute the onset of their symptoms to a stressful event, and one third report sexual and/or physical abuse both in childhood and subsequent adult life.

Consulting behaviour. Approximately half those suffering from symptoms consult a doctor. Those who do consult report more severe symptoms and an increased level of psychological disturbance (anxiety, depression as well sleep disturbance) compared with those who do not.

Abnormal illness behaviour. Patients with IBS have an increased incidence of multiple somatic complaints and frequent consultations for minor illnesses. Patients with IBS are over represented in gynaecology and surgical outpatients and are more likely to undergo inappropriate surgery.

Gut motility. There is no consistent evidence of abnormal motility.

Visceral hypersensitivity. Patients with FGD exhibit evidence of altered CNS processing of visceral pain. 
Postinfective bowel dysfunction. A total of 10$20 \%$ of patients relate onset of symptoms to an acute gastrointestinal illness.

Diet. True food allergy is rare but many patients believe that food intolerances cause symptoms. These beliefs may have either a rational or an emotional basis. The commonest intolerances reported in the UK are wheat, followed by dairy products, coffee, potatos, corn, and onions. Lactose intolerance is found in $10 \%$ of IBS patients but lactose exclusion rarely cures IBS.

\subsection{CLINICAL FEATURES}

Gastroenterological. These include recurrent abdominal pain associated with disturbed bowel habit. Various symptomatic criteria have been defined (see table 1) for clinical trial purposes but do not match the symptoms of all patients. Other criteria such as disturbed defecation are supportive but not essential.

Non-gastroenterological. Lethargy, poor sleep, fibromyalgia, backache, urinary frequency, and dyspareunia are more frequent in IBS and supportive of the diagnosis. Anxiety, depression, and somatisation are frequent but do not reliably discriminate between IBS and other GI diseases.

\subsection{DIAGNOSIS}

Working diagnosis. This can usually be safely made in general practice on the basis of typical symptoms, a normal physical examination, and absence of sinister features (weight loss, rectal bleeding, nocturnal symptoms, or anaemia). This diagnosis should be confirmed in general practice by observation over time.

Supportive features. The diagnosis is more likely if the patient is female, aged $<45$ with a history $>2$ years, and has attended frequently in the past with non-gastrointestinal symptoms.

Table 1 Criteria for diagnosing irritable bowel syndrome

\section{Manning criteria}

(1) Abdominal pain relieved by defecation

(2) Looser stools with onset of pain

(3) More frequent stools with onset of pain

(4) Abdominal distension

(5) Passage of mucus in stools

(6) Sensation of incomplete evacuation

Factor analysis shows the first three symptoms correlate well but are not related to (4), (5) and (6). ${ }^{8}$

Rome I criteria

At least three months of recurrent symptoms of:

(1) Abdominal pain or discomfort relieved with defecation, or associated with a change in stool frequency, or associated with a change in stool consistency and

(2) Two or more of the following on at least $25 \%$ of occasions or days: Altered stool frequency

Altered stool form

Altered stool passage

Passage of mucus

Bloating or distension

It should be recognised that these criteria were drawn up with the support of the

pharmaceutical industry to allow greater comparability between studies of drug effects. They are a consensus and should not become a straitjacket to prevent scientific enquiry. Many patients with abdominal pain and disturbed bowel habit do not exactly fit these criteria, yet their clinical course is similar. The Rome criteria have recently been revised as follows.

Rome II criteria ${ }^{10}$

12 weeks or more in the last 12 months of abdominal discomfort or pain that has two of the following three features:

(1) Relieved by defecation

(2) Associated with a change in frequency of stool

(3) Associated with a change in consistency of stool

The second group of criteria included in Rome I are now considered supportive rather than mandatory in the diagnosis.
2.8 WHEN TO REFER

If symptoms are atypical, the history short, or the patient over 45 , it is usually appropriate to perform further investigations, often via hospital referral.

\subsection{INVESTIGATION AFTER REFERRAL}

Sigmoidoscopy. Those referred to hospital will usually require a sigmoidoscopy if there are colonic symptoms. Any abnormality noted should be biopsied, as should all patients with diarrhoea to detect unsuspected microscopic colitis.

Specific further investigation. Thyroid function, antiendomysial antibodies, stool microscopy, and a urinary screen for laxatives will reveal a limited number of abnormalities ( $1-2 \%$ for each test). If such tests are done, they are best performed on the first visit, avoiding repetitive, anxiety provoking serial testing.

Lactose tolerance testing. This reveals lactose malabsorption in $8-25 \%$ of cases depending on the racial composition of the population but is only indicated if the patient consumes substantial amounts $(>0.5 \mathrm{pint} / 280 \mathrm{ml})$ of milk per day.

Colonic imaging. Patients with a family history of colon cancer or who are older than 45 years at symptom onset should be considered for either a barium enema or colonoscopy if they have colonic symptoms.

2.10 PROGNOSIS

Once a functional diagnosis is established the incidence of new non-functional diagnoses is extremely low.

\subsection{MANAGEMENT AND TREATMENT \\ 2.11.1 Explanation}

Positive diagnosis and reassurance. Most patients will be managed in general practice. The mainstay of management should be a positive diagnosis with an explanation of symptoms and their possible causes, in language the patient can understand with reassurance of a benign prognosis.

Listening to the patient's concerns. It is important to ask the patient what their fears and beliefs are, simply listening may help reduce anxiety. Lifestyle advice. Identifying food fads or deficiencies, including excess or lack of dietary fibre, lack of exercise, and not allowing adequate and suitable time for regular defecation is particularly important at the first consultation in primary care. Most patients referred to hospital will have already tried and failed with such measures.

Placebo response. This is usually substantial (50\%) and gives a false impression of the efficacy of any treatment initially, although this wears off in the following months.

\subsubsection{Dietary manipulation}

Diet advice. Self-imposed dietary restrictions to avoid pain or diarrhoea are common but may be inappropriate. True allergy is rare but intolerance of poorly absorbed carbohydrate, especially lactose and fructose, is well recognised. Excessive caffeine containing beverages may be responsible for some symptoms. 
Exclusion diets. Performed under supervision of an enthusiastic dietitian these may be helpful to a limited number of patients. However, not all offending food items so identified prove to cause symptoms under double blind testing. This suggests that some of the benefit lies in the reassurance and sense of control such regimens provide.

\subsubsection{Psychological therapies}

Identify psychological disorders. This involves a careful history of psychological features, including disorders of mood and sleep and any association of thoughts or feelings with symptoms.

Relaxation therapy. This may help those whose symptoms appear to be "stress related".

Biofeedback, hypnotherapy, cognitive behavioural therapy, and psychotherapy. These may all be used depending on the main features. Those without marked psychiatric abnormalities do best.

Psychiatric referral. If a careful history reveals significant psychiatric disease this should be treated on its own merit. Bowel symptoms may well remit with successful therapy.

\subsubsection{Pharmacological treatments}

Drug treatments. These have a substantial short term response rate, most of which is due to a non-specific placebo component. Specific benefit is seen in only a small proportion of patients.

Abdominal pain. Antispasmodics may help, with those with an anticholinergic effect appearing to be most effective. Alternatively, antidepressant therapy can be given, the efficacy of tricyclics being supported by large clinical trials

Urgency and diarrhoea. This responds well to loperamide or codeine.

Constipation. Usually responds to an increase in dietary fibre. Some patients appear to be specifically intolerant of wheat bran but ispaghula is often better tolerated.

Other drugs. Although commonly used, most have not been shown to have a greater effect than placebo.

\subsection{FUTURE RESEARCH NEEDS}

Compared with other fields, the evidence base is weak and much of the evidence quoted here is at the level of clinical consensus only. Much more research is needed into these common conditions before we can give confident answers to many important clinical questions.

\subsection{Spectrum of functional gastroenterological disorders}

Functional gastroenterological disorders (FGD) are defined by symptoms in the absence of known structural pathology. They have no specific disease marker and their symptoms overlap with those of other diseases. Experienced clinicians often diagnose these disorders on symptoms alone but as functional disorders are so much more common than organic diseases, any diagnostic strategy is likely to have a deceptively high positive predictive value. Typical symptoms include abdominal pain or discomfort and, particularly in hospital patients, a range of non-specific symptoms such as lethargy, anxiety, disturbed sexual function, and disordered sleep. The majority of patients have some features of psychological morbidity, particularly mood disorder.

As there are no specific disease markers, FGD have been categorised according to the likely site of the principal disorder. This ranges from the oesophagus in functional dysphagia, the upper gastrointestinal tract in FD, the colon in IBS, to the anorectum in proctalgia fugax and obstructed defecation. Attempts have been made to further subdivide these disorders into ulcer-like, dysmotility-like, or reflux-like in functional dyspepsia (FD) and into diarrhoea predominant or constipation predominant in the case of IBS. These distinctions reflect the poor understanding of functional disorders rather than evidence of different pathological processes. In reality there is frequent symptom overlap and poor site specific correlation with functional investigations, such as manometry, balloon distension threshold, ${ }^{12}$ intestinal transit, and gastric emptying studies. The same patients may report symptoms typical of both IBS and the various types of FD with variable prominence of the different symptoms over time. ${ }^{3}$ It follows therefore that the overall approach to these conditions should be similar.

\subsection{SOCIAL IMPACT}

Despite the benign nature of these disorders, many functional symptoms such as vomiting, choking, bloating, faecal urgency, incontinence, diarrhoea, flatulence, and borborygmi can restrict social activities and substantially reduce quality of life. Chronic food related pain may lead to refusal of social invitations, while fears about the need for frequent defecation may substantially restrict travel and work. Over $40 \%$ of patients report avoidance of some activities including work, travelling, socialising, sexual intercourse, domestic and leisure pursuits, and eating certain foods as a consequence of their symptoms. ${ }^{4}$ Average work days lost in the USA per year by patients with FGDs were 14.8 compared with 8.7 in the asymptomatic population. ${ }^{5}$ It is this reduction in their quality of life, rather than individual symptoms, which most determines how patients rate the severity of their functional bowel diseases. ${ }^{6}$

There is often a complex relationship between symptoms (table 1) and restricted social activities, with some patients in effect hiding (usually subconsciously) behind these symptoms to avoid situations they find difficult. Patients may experience anxiety and disturbed sleep, with associated lethargy and an "inability to get on with their lives", such that in the worse cases the condition comes to dominate their existence. Difficulty in confirming the diagnosis may lead to further worry and doubt, with numerous visits to doctors and repeated unpleasant tests. A further burden, especially in women, is the risk of unnecessary surgery such as cholecystectomy or hysterectomy, which may aggravate the existing disorder, as well as adding their own specific 
Table 2 Prevalence (\%) of irritable bowel syndrome by sex and number of Manning criteria ${ }^{15}$

\begin{tabular}{lllrlll}
\hline \multirow{7}{*}{} & \multicolumn{2}{l}{ No of symptoms } & & & \\
\cline { 2 - 7 } & 1 & 2 & 3 & 4 & 5 & 6 \\
\hline Male & 27 & 10.7 & 5.0 & 2.3 & 1.3 & 0.9 \\
Female & 46.8 & 24.0 & 13.1 & 6.0 & 2.9 & 1.4 \\
\hline
\end{tabular}

Table 3 Prevalence (\%) of irritable bowel syndrome by symptom frequency and type of pain ${ }^{14}$

\begin{tabular}{lcl}
\hline & $\begin{array}{l}\text { Symptoms } \\
\text { >once a } \\
\text { month }\end{array}$ & $\begin{array}{l}\text { Symptoms } \\
\text { <once a } \\
\text { month }\end{array}$ \\
\hline Male & 11 & 54 \\
Female & 20 & 66 \\
Male+pain relieved by defecation & 5 & 46 \\
Female+pain relieved by defecation & 7 & 55 \\
\hline
\end{tabular}

postoperative complications such as scar pain, adhesions, and surgery related changes in bowel habit.

3.2 FOCUS ON THE IBS AS A MODEL FOR FGD These guidelines concentrate on IBS as this symptom complex is the commonest and best studied of the FGD. However, the principles of investigation and management, particularly of its psychological features, are applicable to all functional disorders. Epidemiology and possible aetiology are discussed in some detail as the most important part of management is explanation, reassurance, and dealing with the associated psychological problems.

\subsection{Epidemiology}

4.1 SEX AND AGE

IBS symptoms are about twice as common in women as men (tables $2-4$ ). The variability in the sex ratio (1.1-2.6) may depend on the weight given to various symptoms as all studies agree that straining and passage of hard stools are commoner in women while frequent and loose stools are commoner in men. ${ }^{11}$ Although the frequency of those reporting abdominal pain together with two or more Manning criteria declined with age over 45 in most studies, ${ }^{5}{ }^{12-14}$ the influence of age appears small and was not seen in a recent large UK study which included over 1800 subjects. ${ }^{15}$ Hence advancing age should certainly be no bar to the diagnosis of IBS although the increasing incidence of other diseases with similar symptoms argues for greater caution in making the diagnosis in the elderly.

4.2 SEVERITY

As the number or frequency of symptoms required for making the diagnosis increases, the calculated prevalence falls (table 2, 3).
Most studies have used either the Rome I criteria or three Manning criteria (which produce closely comparable diagnostic rates). This results in a prevalence of $1.5-12.1 \%$ for men and 5.2-19.1\% for women (table 4).

\subsection{ETHNIC DIFFERENCES}

Ethnic differences have been found in a few studies that have made direct comparisons. IBS appears to be more common in Japan than Holland $(25 \% v 9 \%)^{16}$ and in Whites compared with Hispanics in the USA $(21.8 \% v 16.9 \%)^{17}$ but similar in US Whites and Blacks. ${ }^{8}$ One study of students in Nigeria showed a particular high prevalence of symptoms $(48 \%$ in women and $24 \%$ in men using two Manning criteria) but this may have been due to the high incidence of gastrointestinal infections in this population. ${ }^{18}$ By contrast, subjects from rural Thailand appear to have a much lower risk. ${ }^{19}$ Cultural factors including diet and socioeconomic status are important; thus in the bicultural city El Paso on the US/Mexican border, US Whites are more likely to report symptoms than Hispanics, but after controlling for socioeconomic and dietary differences this ethnic difference was no longer significant. ${ }^{20}$

\subsection{Aetiology}

5.1 OVERVIEW

It is highly likely that within the group of patients with functional bowel disease there are as yet unrecognised infectious and other organic causes of bowel disturbance. We should not therefore expect all patients to show similar features or predisposing factors. However, for many patients the two most consistent, and probably interrelated, characteristics are psychological morbidity and visceral hypersensitivity. A substantial minority may relate the onset of symptoms to an acute gastrointestinal illness, while a further minority report that specific dietary components precipitate symptoms.

\subsection{PSYCHOLOGICAL MORBIDITY}

Most cases seen in general practice do not have major psychological morbidity. Those who progress to outpatients have a higher incidence of psychological symptoms and psychiatric disease, the most floridly abnormal being found in long term follow up in those attending academic departments. ${ }^{24}$ Compared with healthy controls, these IBS patients have higher scores for anxiety, hostile feelings, sadness, depression, interpersonal sensitivity as well as more sleep disturbance. ${ }^{25-28}$ However, part of this is due to the fact that more anxious

Table 4 Prevalence (\%) of irritable bowel syndrome in the USA using three Manning or the Rome criteria

\begin{tabular}{|c|c|c|c|c|c|c|}
\hline Reference No & Group characteristics & $n$ & Diagnostic criteria & $\begin{array}{l}\text { Total (\%) } \\
\text { IBS }\end{array}$ & $\begin{array}{l}\text { Men }(\%) \\
I B S\end{array}$ & $\begin{array}{l}\text { Women (\%) } \\
\text { IBS }\end{array}$ \\
\hline 21 & US White & 835 & 3 Manning & 12.8 & 12.1 & 13.6 \\
\hline 15 & UK White urban & 1896 & 3 IBS symptoms & 9.5 & 5.0 & 13.0 \\
\hline 8 & US students & 1344 & 3 Manning & 15.5 & 9.6 & 18.3 \\
\hline 12 & US elderly & 328 & 3 Manning & 10.9 & NA & NA \\
\hline 22 & US health examinees & 1264 & 3 Manning & 3.6 & 1.5 & 5.2 \\
\hline 23 & US students & 789 & 3 Manning & 11.7 & NA & NA \\
\hline 5 & US $95 \%$ White & 5430 & Rome & 9.4 & 7.7 & 14.5 \\
\hline
\end{tabular}


patients are more likely to seek a second opinion as IBS sufferers who do not consult any doctor are not psychologically different from controls. ${ }^{29}$ Compared with outpatients with organic gastroenterological disease, there are no consistent differences and psychiatric features cannot be used reliably to distinguish functional from organic disease. ${ }^{30} 31$

Several studies have investigated the prevalence of adverse life events and in particular sexual abuse in these patients. More than 50\% linked the onset of their symptoms to a stressful event such as employment difficulties, family death, a surgical procedure, or marital stress, and a similar proportion reported concurrent social problems relating to work, finances, housing, and personal relationships. ${ }^{4}$ A history of sexual abuse, often combined with physical abuse, both in childhood and subsequent adult life has been reported in $20-30 \%$ of patients with IBS, significantly more commonly than in the general population $(<10 \%)$ or in patients with organic disease $(14 \%))^{32} 33$ Adverse life events prior to the onset of IBS are as common as in patients with deliberate self-poisoning and significantly more common than in patients with organic gastrointestinal disease ${ }^{34}$ Significantly, the psychiatric illness or adverse life event preceded the onset of the bowel disorder in two thirds of patients. ${ }^{28}$

5.3 ABNORMAL ILLNESS BEHAVIOUR

Not all patients with symptoms consistent with IBS consult a doctor; consultation rates vary from $10 \%$ to $50 \%$ depending on age and sex. ${ }^{131535}$ As expected, patients with more symptoms and more severe pain were more likely to consult, ${ }^{15}$ as were those with more psychological symptoms. ${ }^{36}$ This relationship between psychosocial disorders and frequent attendance at outpatient clinics is true for many disorders and is not unique to IBS. ${ }^{30}$ As expected, those who reach outpatients are more likely to believe that their illness is not stress related and are therefore more fearful of organic disease. ${ }^{38}$

Patients with FGD also consult their doctors more often for non-GI complaints than patients without FGD. ${ }^{5}$ Non-gastroenterological features such as lethargy, poor sleep, fibromyalgia, backache, urinary frequency, and dyspareunia are more frequent in IBS and supportive of the diagnosis. Patients with IBS and lower abdominal pain are over represented in gynaecology and surgical outpatients ${ }^{39}$ but are less likely to have recognisable pathology ${ }^{40}$ and more likely to undergo surgery. ${ }^{41}{ }^{42}$ Studies of this abnormal illness behaviour have found a record of multiple somatic complaints and inappropriate consultations for minor illnesses. ${ }^{43}$ There were significantly higher abnormal illness behaviour scores in IBS patients compared with those with organic disease or patients consulting specifically for depression. ${ }^{27}$ This negative interpretation of innocent sensations is consistent with the observation that patients with IBS were biased towards remembering terms with negative connotations. ${ }^{44}$ This may well explain why objective measures of disturbed function such as rapid colonic transit or increased rectal sensitivity relate so poorly to symptoms but relate better to psychological features. ${ }^{45}$

Patients' complaints of ill health may reflect their experience of others with similar symptoms or previous experience of the secondary gain associated with being ill themselves. Studies of children with chronic abdominal pain have found an association with poor health and emotional disorders in their parents. ${ }^{46}{ }^{47}$ People who recalled being given gifts or special foods when they were unwell as a child were more likely to exhibit chronic illness behaviour and more likely to have IBS as adults. ${ }^{43}$

5.4 EFFECT OF MOOD ON GI FUNCTION

Most people have, at some time or other, experienced the effect of anxiety on gut function, including cramps and diarrhoea. Animal studies have shown that stress inhibits small bowel transit while accelerating colonic transit and causing increased stool frequency. ${ }^{48}$ Depressed patients have delayed small bowel and whole gut transit, with a correlation between transit time and severity of depression, while anxiety is associated with accelerated small bowel transit. ${ }^{49}$ Acute stress is difficult to model in an ethical experiment but in healthy volunteers acute stress disrupts normal fasting motor patterns ${ }^{50}$ and accelerates small bowel transit. ${ }^{51}$ It also stimulates the colon of both normal subjects and IBS patients, although until recently it has been difficult to demonstrate any consistent difference between the two groups. ${ }^{52-54}$ Over the past decade evidence has accumulated showing that the cathartic effect of severe stress in rats is mediated largely through release of corticotrophin releasing factor. $^{55-57}$ This has made it possible to mimic the effect of severe stress on the human colon by using an infusion of corticotrophin releasing factor which increases descending colon motility indices and induces abdominal pain. When this was done, the IBS patients' colonic responses were greater and they experienced more pain than normal subjects, ${ }^{58}$ an interesting finding which needs confirming.

Stress has not been convincingly shown to alter perceptual thresholds to balloon disten$\operatorname{sion}^{59}$ but relaxation and hypnosis can raise the threshold for discomfort, while hyperventilation has been shown to lower discomfort thresholds. ${ }^{60}$

\subsection{ABNORMAL AUTONOMIC REACTIVITY IN IBS} Altered autonomic reactivity has been noted in IBS, with decreased vagal tone associated with constipation $^{6162}$ and increased sympathetic activity associated with diarrhoea. ${ }^{63}$ These observations provide a mechanism whereby psychological abnormalities could be translated into differences in transit. The potential role of autonomic dysfunction in IBS is made more plausible by the report from the Mayo Clinic of eight patients with acute autonomic neuropathies who presented with apparently typical IBS symptoms. ${ }^{64}$ 
5.6 EVIDENCE OF ABNORMAL GUT MOTILITY IN IBS Early studies suggested abnormal electrical control activity in the colon ${ }^{65}$ but this was not substantiated by later workers. ${ }^{667}$ As with non-IBS constipated patients, constipation predominant IBS patients have been reported to have decreased high amplitude propagated colonic contractions. ${ }^{68}$ However, sigmoid contractility is increased in some patients ${ }^{69}$ and this may cause increased resistance to caudal flow. Exaggerated response to emotion has also been reported ${ }^{70}$ but this difference from controls was not consistent, ${ }^{71}$ perhaps due in part to the difficulty in inducing strong emotions reliably while remaining within boundaries set by ethical constraints (see preceding section). Inadequate means of scoring and assessing colonic pressure profiles may also contribute to the difficulty in showing consistent differences as transit studies have generally shown fast and slow transit in diarrhoea and constipation predominant IBS, respectively. ${ }^{72}$ However, it should be noted that in spite of fast transit, most stool weights in IBS patients lie within the normal range ${ }^{73} 74$ even in those with diarrhoea as their main complaint. ${ }^{75} 76$

Interest in possible small bowel abnormalities were stimulated by initial reports that discrete clustered contractions were commoner in IBS and associated with symptoms. ${ }^{77} 78$ However, these have not been confirmed by others ${ }^{79}$ although the later study examined only fasting activity when symptoms are less frequent.

Recently there has been an increasing emphasis on altered sensation as the basis for symptoms as it has become clearer that symptoms correlate poorly with objective measures such as stool weight and transit.

5.7 VISCERAL HYPERSENSITIVITY

Patients with FGD exhibit decreased pain thresholds to balloon distension of the gut. This was first described in the rectum of patients with IBS 25 years $\mathrm{ago}^{80}$ and subsequently confirmed by others ${ }^{81}$ and is often noted with air insufflation during colonoscopy. ${ }^{82}$ Similarly, patients with FD have a lower threshold to balloon distension of the stomach. ${ }^{83}$ This visceral hypersensitivity is not site specific and has been demonstrated in the oesophagus of patients with IBS as well as in the rectum of patients with FD. ${ }^{84}$ These changes are specific to gut stimulation as somatic pain thresholds to extreme cold or transcutaneous electrical stimulation are either normal or even increased in some studies. ${ }^{81} 8485$ This was thought to indicate an abnormality of mucosal sensitivity in the gut but as studies have become more sophisticated to try to eliminate external influences on patient perception, this opinion has changed. IBS patients are much more likely to show an increased sensitivity when the rectum is distended in a predictable sequence of increasing volumes than when it is distended with volumes chosen in a random iterative method. This indicates a response bias, which may be related to a patient's apprehension of pain rather than any peripheral and objective increase in sensitiv- ity. ${ }^{86}$ These studies suggest that IBS patients describe gut stimuli as unpleasant or painful at lower intensity levels compared with normals, a phenomenon which is likely to originate centrally rather than peripherally.

The central processing of visceral afferents has been assessed using positron emission tomography (PET scanning) and more recently functional magnetic resonance imaging to measure the resulting regional cerebral blood flow. Most of the relevant studies have as yet only been presented in abstract form. The one published study compared the effects of actual and sham distension of the rectum in healthy volunteers and IBS patients on cerebral blood flow. Perception of pain during both actual and simulated delivery of painful stimuli in healthy subjects was associated with activation of the anterior cingulate cortex (ACC) whereas no ACC response was seen with nonpainful stimuli. IBS patients in this study showed no consistent activation during either painful or non-painful distension but demonstrated significant activation of a different region, the left prefrontal cortex, when anticipating painful stimulation due to sham distension. ${ }^{87}$ This and other evidence suggests that normally the ACC has an important role in mediating the affective qualities of visceral pain, both intestinal and cardiac, and that this response is abnormal in IBS and other painful functional disorders such as fibromyalgia. Subsequent studies have produced conflicting data so plainly this area is still evolving. Abnormal central processing may provide a mechanism which could explain the association between IBS and mood, psychological stressors as well as disease beliefs and expectations.

5.8 POSTINFECTIVE BOWEL DYSFUNCTION

A subgroup of IBS patients report that their symptoms began after an acute gastrointestinal illness, a group which appeared to have a slightly better prognosis in two retrospective analyses. ${ }^{88}{ }^{89}$ Persistent bowel dysfunction was noted in $25 \%$ of patients following documented Campylobacter, Shigella, and Salmonella $^{90}{ }^{91}$ gastroenteritis. Two separate studies reported that $38 \%$ and $29 \%$ of patients with enteritis developed IBS. ${ }^{4591}$ Factors predisposing to persisting symptoms included a physically more severe acute illness ${ }^{90}$ as well as greater anxiety and adverse life event scores in the six months leading up to the acute illness. ${ }^{45}$ Increased sensitivity to rectal distension was also reported after the infectious illness. ${ }^{45}$ While macroscopically normal, microscopic abnormalities are detectable in rectal biopsies using special stains, the significance of which is under investigation. This phenomenon is not unique to IBS, cystitis being another example of a disease in which inflammation appears to increase visceral sensitivity. ${ }^{92}$ The conclusions of these studies have recently been supported by a prospective study of over 584000 patients in whom it was shown that when a range of demographic details were examined, a bout of culture positive bacterial gastroenteritis emerged as the strongest predictor of new 
onset IBS, with a relative risk of 11.9 (95\% CI $6.7-21) .{ }^{93}$

5.9 DIET

Patients often relate their functional symptoms to certain foods and some have considerably restricted their diet by the time they consult. The patient's beliefs may have either a rational or emotional basis. The evidence that the gut is in some way sensitive to particular foods is limited. Food is chemically highly complex and response to food exclusion is poorly reproducible, leading desperate patients to more and more restricted and illogical diets. Such circumstances make patients easy prey to unscrupulous practitioners and there are many "fringe" practitioners benefiting from the confusion.

Studies that have used dietary restriction followed by sequential introduction of single foods have reported specific food intolerance in $33-66 \%$ of IBS patients. ${ }^{94} 95$ The commonest intolerance reported in the UK is to wheat, followed by dairy products, especially cheese, yoghurt and milk, coffee, potatos, corn, onions, beef, oats, and white wine. ${ }^{94}$ Ingestion of osmotically active, poorly absorbed fermentable carbohydrates such as lactulose is known to cause typical IBS symptoms such as bloating, cramps, and diarrhoea. A recent study showed increased colonic hydrogen production in IBS. An exclusion diet was reported to reduce both symptoms and gas production in response to a standard dose of lactulose implying that the diet modified the fermentation capabilities of colonic bacteria. ${ }^{96}$ The indirect nature of this response to diet may explain why the clinical benefit varies as the bacterial flora is itself so variable.

Adult acquired hypolactasia is common in the UK, with an incidence of $10 \%$ in those of Northern European descent, rising to $60 \%$ in Asians, and $90 \%$ in Chinese patients. Regional differences in dairy intake may account for the variable benefit reported with lactose free diets in IBS. Thus in Denmark, with a traditionally high intake of dairy products, a low lactose diet has been reported to produce improvement in 13 of 20 Danish adults with symptoms of IBS and objective evidence of lactose malabsorption. ${ }^{97}$ However, only subjects ingesting a substantial amount of lactose (equivalent to more than 0.5 pint of milk per day) can expect to benefit from lactose restriction as lower amounts do not cause symptoms, even in lactose malabsorbers. ${ }^{98}$

An initial study using elimination diets (that is, diets that eliminate all but a single fruit, meat, vegetable, etc) improved symptoms in $67 \%$ of those who completed the study. More practicable exclusion diets, which make less demands on the patient, have been developed which only exclude foods that had commonly been implicated in food intolerance from the earlier studies (for example, wheat, milk, coffee, potatos, corn, onion, beef, oats, cheese, and white wine). Such studies had a lower success rate $(48.2-50 \%)$ with similar compliance rates.
The validity of these studies of food intolerance is hard to evaluate as a placebo response cannot be excluded unless a double blind food challenge is performed. Such studies, which involve blind challenge with blended foods passed down nasogastric tubes, bypass the important social, psychological, and physical aspects of eating, which are likely to be at least as important as the direct effects of individual food constituents on the gut. They are really only valid in identifying food allergy as the relatively small amounts of material instilled are not enough to elicit symptoms in cases of food intolerance. An early study using nasogastric delivery of suspected food reported six of 25 consecutive IBS patients who correctly identified food triggers and showed an increase in prostaglandins in rectal dialysate. ${ }^{95}$ However, a subsequent study of 13 patients who had identified a food intolerance by means of an exclusion diet found a high placebo response with only three patients showing a significant ability to identify food triggers when administered double blind. ${ }^{99}$

True food allergy is much less common and usually not difficult to recognise if food ingestion is associated with urticaria, asthma, eczema, angioedema, and rhinorrhoea with a high incidence $(70 \%)$ of positive skin prick or high RAST scores. ${ }^{100}$ Such patients usually see an immunologist rather than a gastroenterologist and are not usually thought to have IBS. When symptoms were purely gastroenterological, only 15 of 88 who believed they were allergic actually had their perceptions confirmed by double blind trial. ${ }^{101}$ It is worth noting that those who respond immediately to food ingestion are more likely to have positive skin tests than those who report symptoms which come on some hours after food ingestion. ${ }^{102}$ Positive skin prick testing for common food antigens has been reported in up to a third of patients with IBS and these patients have been reported to respond better to elimination diet and type I hypersensitivity inhibitors such as sodium cromoglycate. ${ }^{103}$ These results need confirming before definitive conclusions can be drawn. ${ }^{104} \mathrm{It}$ should be recognised that in only a minority of cases is the patient's beliefs confirmed objectively, so some of their response must be psychologically determined. Recent studies showing that mast cell degranulation can be psychologically triggered ${ }^{105}$ together with evidence that food allergy patients degranulate jejunal mast cells in response to cold stress ${ }^{106}$ open the way for a possible explanation whereby stress or patient's beliefs about food might trigger a gastrointestinal response.

\subsection{Diagnosis}

Functional gastroenterological disorders are common but only about half actually consult their general practitioner ${ }^{107}$ and of these only about one in five are referred to a hospital consultant in any given year. Most assessment and management is therefore carried out in general practice. Unfortunately, most published evidence relates to patients referred to hospital. 
6.1 DIAGNOSIS AND MANAGEMENT IN GENERAL PRACTICE

A careful and detailed history, often accrued over several short interviews and sometimes over many months or even years, is required. This will take account of psychological factors, past family and personal history, as well as the social circumstances of the patient, which the general practitioner is uniquely placed to assess. The patient aged less than 45 years who describes typical symptoms (fig 1) without sinister features, such as weight loss, rectal bleeding or symptoms responsible for night time waking, probably has FGD. This should be supported by a normal physical examination including, where relevant, rectal examination and no evidence of anaemia. The diagnosis is more likely if the patient is female, has a history of greater than two years, and has attended frequently in the past with non-gastrointestinal symptoms such as malaise and backache. If symptoms are typical then no further investigations are necessary to establish a working diagnosis. However, if there are atypical features or the history is short, it may be appropriate to perform some of the screening tests referred to below.

A typical history with or without negative test results should lead to a firm diagnosis with detailed explanation and reassurance, preferably without new medication, followed by further review if symptoms continue. Simple pharmacological or dietary interventions may be appropriate for some patients at that time. Most symptoms will resolve, or remain unchanged but acceptable, and need no further attention.

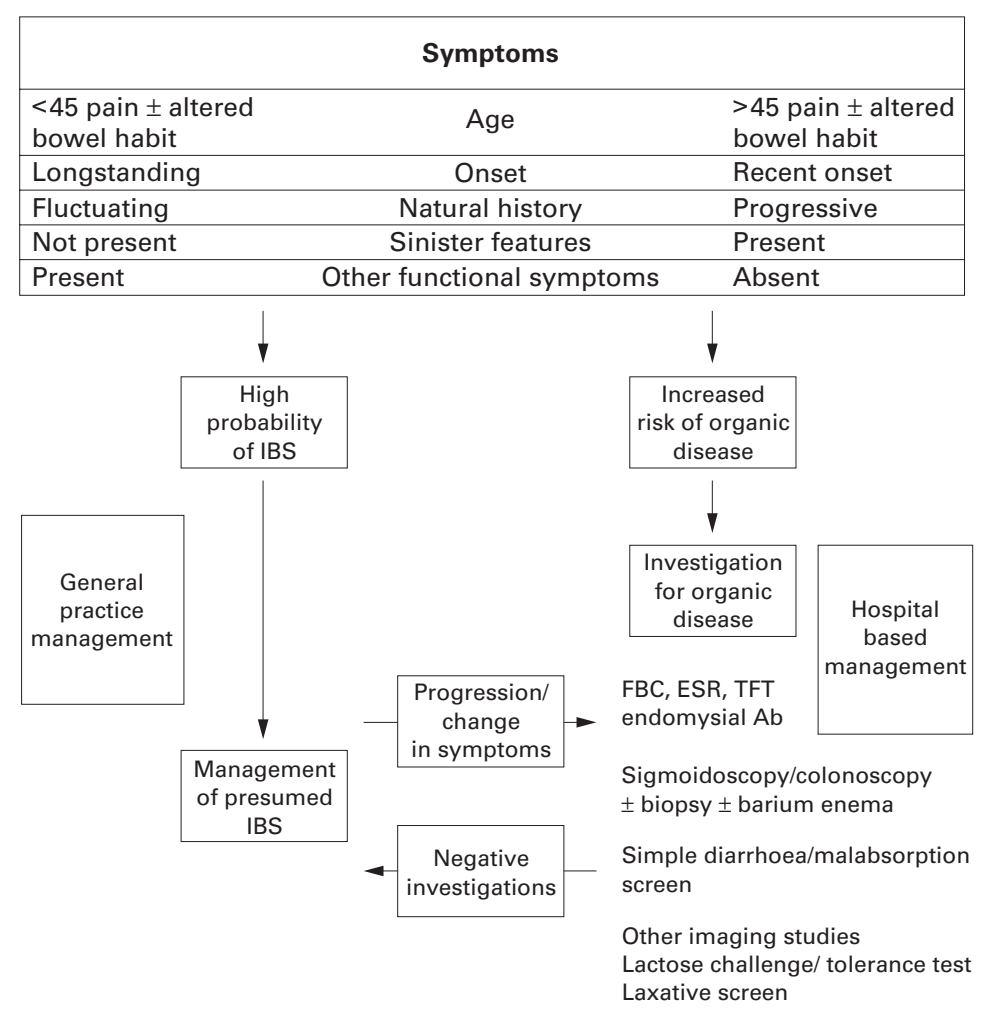

Figure 1 Stages in the evaluation of the irritable bowel syndrome (IBS).
6.2 WHEN TO REFER

Patients presenting for the first time in later life and those with atypical symptoms normally warrant hospital referral. However, some patients in whom the general practitioner has made a confident diagnosis of FGD develop further symptoms or worsening anxiety, often related to adverse life events such as bereave-

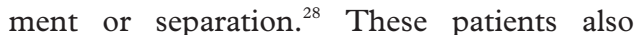
warrant referral to help exclude an alternative diagnosis and to provide more definitive reassurance than the primary care physician can offer. The general practitioner is well placed to understand the illness in the wider context of the patient's life, and it is important that this information is transmitted frankly and comprehensively to specialists when referral is needed. The skilled general practitioner will recognise that these patients commonly have complaints relating to several systems, and will avoid the fragmentation of care that so easily occurs if every new complaint results in referral to a different specialist.

6.3 DIAGNOSIS IN HOSPITAL SETTING

Although functional disorders account for $36-50 \%$ of all outpatient consultations, the filtering process means that the incidence of other diseases is higher than in general practice and therefore further investigations are often indicated.

Symptom criteria such as those devised by Manning differentiate IBS reasonably well from normal subjects or patients with peptic ulcer or reflux ${ }^{71}$ but do not reliably distinguish IBS from inflammatory bowel disease. ${ }^{108-110}$ Thus symptoms alone cannot be relied upon but must be augmented by physical examination, demographic data such as age and sex, together with the progression of symptoms over time, all of which strongly influence the a priori probability of the different diseases from which IBS must be distinguished. The most important diagnosis not to be missed is cancer and as age and family history are the main risk factors, these will have a strong influence in deciding who to investigate.

A careful dietary and drug history is vital to identify unusual dietary habits or new medications whose use may have preceded the development of symptoms. Particular attention should be given to low/excess intake of dietary fibre, or excess of poorly absorbed sugars such as fructose or sorbitol or stimulants such as coffee or tea. Similarly, a wide range of drugs can cause bowel disturbance with diarrhoea and/or abdominal discomfort, such as angiotensin inhibitors, $\beta$ blockers, antibiotics, chemotherapeutic agents, proton pump inhibitors, or NSAIDs, while constipation may be related to opiate analgesics, calcium channel blockers, or antidepressants with anticholinergic effects, to mention just a few. Although it is common to find a positive family history of IBS this is not unexpected in so common a condition and no study has shown this to be of any diagnostic help.

Patients with conventional IBS symptoms such as those described by Manning, or those that fulfil the Rome I criteria who have no 
alarm symptoms and no abnormal findings on physical examination in the hospital setting have a $52-74 \%$ chance of having IBS. ${ }^{31111}$ Non-gastroenterological features such as lethargy, poor sleep, fibromyalgia, backache, frequency and urgency of micturition, nocturia, incomplete bladder emptying, an unpleasant taste in the mouth, early satiety, and dyspareunia are all commoner in IBS than controls and supportive of the diagnosis. ${ }^{112-114}$ Many authors have drawn attention to the striking disparity between the proclaimed severity of symptoms and patient's desperation with their otherwise healthy appearance. Phrases like " symptoms ruling my life", “ desperation", "you must do something" will strike a cord with many experienced practitioners.

Although as already indicated, abnormal levels of anxiety, depression, and somatisation are features of many patients who are referred to hospital, these features do not discriminate between IBS and other GI diseases. ${ }^{30}$ Inquiring about these emotionally disturbing features is usually inappropriate at the first visit but may be worth exploring when initial tests are unrewarding.

Although specificity of diagnosis after a history and physical examination has been reported to be improved to over $95 \%$ by using a scoring system that includes full blood count (FBC) and erythrocyte sedimentation rate (ESR), ${ }^{115}$ others have not found such good discrimination. ${ }^{116}$ Sigmoidoscopy, which can be done at the first clinic visit, should exclude those with ulcerative colitis or rectal cancer. If the rectum appears macroscopically normal, routine rectal biopsy does not usually add anything. ${ }^{117}$ However, in those with diarrhoea as a major complaint, it should be performed as it may provide evidence of microscopic colitis which may alter management significantly. ${ }^{118}$

\subsection{FURTHER INVESTIGATIONS}

How many further investigations beyond a simple blood count are performed depends on what is considered to be an acceptable level of missed diagnoses. A "screen" including thyroid function, stool microscopy for ova, cysts, parasites and fat globules, and flexible sigmoidoscopy with colonic biopsy, together with lactose tolerance testing in a large (1452 patients) American study of patients fitting IBS criteria gave a yield of $6 \%$ thyroid abnormalities (3\% hyperthyroid, 3\% hypothyroid), occult inflammatory bowel disease in $1 \%$, and evidence of lactose malabsorption in $21-25 \% .{ }^{119}$ Patient reports of lactose intolerance relate poorly to objective evidence of lactose malabsorption and cannot be relied upon. ${ }^{120}$ It would therefore be logical to perform a breath hydrogen test for lactose malabsorption on IBS patients who are regular consumers of more than 0.5 pint (280 $\mathrm{ml}$ ) of milk or equivalent dairy products, especially if they come from a racial group with a high incidence of lactose malabsorption. Alternatively, the response to lactose exclusion may be helpful although the result is usually less clear cut than the breath hydrogen test. Other simple screening tests which are logical include ESR, calcium and albumin, and antiendomy- sial antibodies, but there is no published evidence as to their yield, which is likely to be low $(1-2 \%)$. However, it should be borne in mind that cheap tests with a low yield may yet be cost effective.

Patients with high stool weight $(>200 \mathrm{~g}$ daily) should have a laxative screen, which in some series is positive in about $15-26 \%$ of such cases. $^{121122}$

\subsection{IMAGING}

Colonic cancer is not reliably excluded ${ }^{110}$ by history, and patients with a positive family history or who are older than 45 years at symptom onset (when the incidence of sporadic colon cancer begins to rise steeply) should be considered for either a barium enema or colonoscopy. Ultrasound rarely detects a relevant alternative diagnosis in patients with suspected IBS and is not recommended as it uncovers coincidental asymptomatic abnormalities such as gall stones and fibroids in $8 \% .{ }^{123}$ This may easily lead to inappropriate surgery with no benefit to symptoms. Small bowel Crohn's disease in its early stages is easily confused with IBS and barium follow through should be considered for patients with worsening symptoms or suspicion of an abdominal mass, particularly if there is anaemia or elevation of ESR or C reactive protein. However, it should be remembered that this examination exposes the ovaries to appreciable radiation and it should be used sparingly in young females.

\subsection{FUNCTIONAL TESTS}

Various measures of gut function, including bile acid absorption (SeHCAT seven day retention) and gut transit have been shown to be abnormal in functional diarrhoea but are not widely used in typical IBS. One study reported that five of 42 patients with functional diarrhoea retained $<8 \%$ SeHCAT and responded to cholestyramine. ${ }^{124}$ More recently, patients with unexplained diarrhoea and stool weights $>200 \mathrm{~g}$ were shown to have reduced bile acid retention. ${ }^{125}$ Ileal and colonic biopsies have yielded inconsistent results and at present it seems likely that low retention in most cases is non-specifically related to fast small bowel transit. ${ }^{126}$ Rare isolated defects in bile salt absorption have been described ${ }^{127}$ but are unlikely to be responsible for more than a very few cases of IBS.

\subsection{PROGNOSIS}

Once the diagnosis is established the incidence of new significant diagnoses is extremely low. Harvey et al found no significant new diagnoses in 104 patients followed for five years, the diagnosis being largely based on symptoms, as only $12 \%$ of these had radiological studies. ${ }^{89}$ Another study of 112 patients in which the majority had extensive radiological studies reported only two initial misdiagnoses of IBS (one chronic pancreatitis and one carcinoma of the pancreas). Five years later one case of thyrotoxicosis and one of gall stones had become apparent, values probably no different from the expected incidence of disease in initially healthy controls over a five year period. Thus 


\section{Recommendations}

- Young patients (<45 years) with typical functional symptoms, no alarm symptoms or family history of colonic cancer, and a normal examination can be safely given a working diagnosis of IBS without further tests and their response to reassurance and lifestyle advice observed. (Recommendation grade B.)

- Those referred to hospital with more severe symptoms usually require further investigation including at least sigmoidoscopy, FBC, and ESR. (Recommendation grade $\mathrm{B}$.)

- Patients with diarrhoea should be fully evaluated with non-invasive investigations such as serum B12, red cell folate, ferritin, thyroid function, antiendomysial antibodies, calcium, albumin, and microscopy of the stool together with a rectal biopsy and where appropriate barium follow through. Severe diarrhoea warrants a full colonoscopy to exclude microscopic colitis. (Recommendation grade C.)

- Older patients with recent onset of symptoms or younger subjects with a family history of colon cancer usually justify imaging of their colon. Progressive symptoms in any age group should prompt re-evaluation of the need for further imaging. (Recommendation grade C.)

the chance of remaining free of serious disease in IBS is excellent.

The prognosis for continuing abdominal symptoms is however less good and depends on the criteria used, with about $30 \%$ still symptomatic at five years in Harvey's study ${ }^{89}$ but only $5 \%$ of patients completely symptom free in a Danish five year follow up study. ${ }^{14}$ Symptoms vary both in severity and quality with time. Thus a substantial proportion of individuals with IBS symptoms in the community experience loss of IBS symptoms over 12 months but may develop other functional symptoms such as FD. ${ }^{3}$ Factors that have been shown to worsen prognosis include more prominent psychological symptoms ${ }^{88}$ and a longer history of illness ${ }^{24}$ as well as previous abdominal surgery. ${ }^{128}$

\subsection{Management and treatment}

Most of this will be carried out in general practice (fig 1). The mainstay is explanation and reassurance in terms that the patient can understand, together with sensible lifestyle adjustments relating to diet, medications, and stressors, which appear to precipitate symptoms.

7.1 POSITIVE DIAGNOSIS AND EXPLANATION Making a definite diagnosis helps both doctor and patient by reassuring them that it is unlikely that another alternative diagnosis will emerge over the ensuing years. ${ }^{89}$ However, this not does make the symptoms disappear and the patient may continue to need a supportive understanding relationship with a physician.
7.2 LISTENING TO THE PATIENT

Simply listening to the patient and accepting that their symptoms are real and valid may help, especially if previous consultations have been unsatisfactory. It is important to ask the patient about their fears and beliefs. A high proportion believe there is some serious disease, in particular cancer. The condition needs to be explained simply using analogies with which a layman can relate. Cramps and spasms are easily accepted as causes of pain. Most can understand how anxiety, such as before a test or examination, can cause diarrhoea. This can be used to introduce the idea of brain-gut interactions. Explanation of possible mechanisms such as "sensitive gut" or reaction to infection, if put in simple terms, reduces anxiety caused by unexplained symptoms and is usually highly valued by the patient. At a minimum, this prevents further unnecessary referrals and possibly hazardous treatments, such as hysterectomy or cholecystectomy. Although accepted by many clinicians, these concepts have not been subjected to proper randomised controlled trials.

\subsection{LIFESTYLE ADVICE}

This will be much more important at first presentation in primary care than in hospital practice, when most will already have tried and failed such measures. This will include a careful dietary and lifestyle history, identifying food fads or deficiencies, including excess or lack of dietary fibre. Lack of exercise and not allowing adequate and suitable time for regular defecation are common problems which are especially relevant to constipated IBS sufferers. Keeping a two week diary of symptoms, stresses, and dietary intake may identify aggravating factors and will be helpful in discussing management. Those with constipation/ diarrhoea need advice about intake of "fibre" or poorly absorbed non-starch polysaccharides, fructose, sorbitol or lactose, which may be either increased or decreased with benefit. Intake of drugs and herbal medicines, which may affect the bowels, should also be noted.

\subsection{PLACEBO RESPONSE}

Defining the best treatment in IBS has been difficult, at least in part because the placebo response is so marked, averaging $47 \%$ in a recent survey of 25 randomised controlled drug trials. This effect was approximately three times larger than the additional drug effect, which was $16 \%{ }^{129-132}$ However, the longer the follow up the smaller the placebo effect becomes and as yet long term benefit has only been shown for psychological and dietary treatments. The high placebo response during clinical trials may reflect the effect of the greater contact between the patient and health care professionals. Compared with routine outpatient clinics, much more time is available for explanation, reassurance, and general discussion. The value of reassurance in IBS has not been studied systematically but in FD the patients' responses to reassurance that they do not have serious disease depends on psychological factors. Thus while patients with low or 
moderate anxiety do well with the reassurance provided by negative endoscopy, the benefit to those with marked anxiety is short lived. ${ }^{133}$ These patients, whose quality of life remains poor despite reassurance and explanation and in whom psychological features appear prominent, may respond to more formal psychological treatments. Several forms of therapy have been studied in IBS but studies which have not used a suitable placebo are difficult to interpret as in the short term at least, any form of increased patient contact has a non-specific beneficial impact. ${ }^{134}$

7.5 DIETARY FACTORS

Many patients believe that some dietary item is responsible for symptoms and some have adopted inappropriately restrictive diets. Equally, some patients have excessively large intakes of indigestible carbohydrate, fruits or caffeine, and these patients may benefit from simple dietary advice. Others, particularly patients of non-European descent, may have hypolactasia. Those with a substantial intake of lactose ( $>0.5$ pint $(280 \mathrm{ml})$ milk/day) may benefit from a low lactose diet. Rarely, excessive intake of fructose may cause symptoms due to slow or incomplete absorption which could cause gut distension to which IBS patients appear especially sensitive. ${ }^{135}$ Bloating is an extremely common symptom in the normal population, being reported as frequent by $10-20 \%$, with an excess in women. ${ }^{12}{ }^{14} \mathrm{It}$ responds poorly to drugs but may respond to the dietary measures outlined above.

Exclusion diets may benefit some patients but are arduous and must be supervised by an enthusiastic dietitian. Treatment begins with a detailed diet history, followed by a strict exclusion diet supported by a food and symptom diary, and telephone contact with the dietitian. The exclusion diet omits a range of foods ${ }^{136}$ (for example, dairy, citrus, and grains), including any the patient believes to provoke symptoms for a period of two weeks. This is followed by reintroduction of single foods to identify which, if any, precipitate their symptoms. An individualised diet can be produced for each patient, avoiding foods to which they are intolerant. Two large studies using this approach have found long term remission in approximately $50 \%$ of patients. There was however no symptom monitoring or attention placebo controls so the results may have been nonspecific. ${ }^{94136}$

\subsection{PSYCHOLOGICAL THERAPIES}

These range in their depth and ambition from a limited attempt to control symptoms with simple behaviour therapy, through hypnosis, to insight oriented psychotherapy. It should be recognised that the availability of the more time consuming techniques is limited in the NHS and their use should therefore be restricted to only the most difficult cases.

7.7 RELAXATION THERAPY

This is the simplest form of "psychotherapy" which can easily be taught to patients by audiotapes. The logic is that if stress causes functional

\section{Recommendations}

- Simple dietary advice will benefit some patients with diarrhoea who have excessively large intakes of indigestible carbohydrate, fruits, or caffeine. (Recommendation grade C.)

- Constipated patients with low fibre intake should be given a trial of a high fibre diet. (Recommendation grade C.)

- Those with diarrhoea, whose intake of lactose is substantial $(>0.5$ pint $(280 \mathrm{ml})$ milk/day) may benefit from a trial of lactose exclusion and/or a lactose tolerance test. (Recommendation grade B.)

- Formal exclusion diets may be useful in controlling symptoms in some patients. (Recommendation grade B.)

bowel disorders, reducing autonomic arousal by relaxation reduces symptoms and induces a sense of well being, allowing the patient to feel more confident and in control. Patients are taught to exclude sources of tension and relax. Unfortunately, there are few controlled studies and most include very small numbers of patients but Blanchard et al showed that 10 sessions of progressive muscle relaxation over eight weeks reduced symptoms compared with a placebo control of symptom monitoring visits alone. ${ }^{137} \mathrm{~A}$ further study showed that relaxation training reduced symptoms and, most importantly, the number of medical consultations during a 40 month follow up. ${ }^{138}$

7.8 BIOFEEDBACK

This, in theory at least, depends on feedback of a measure of visceral function to show the patient a disturbance in physiology so that they can learn to correct it. It has been used most commonly in the treatment of incontinence and constipation. Therapy aims to make the patient more sensitive to rectal sensation and avoid inappropriate straining. It also provides a detailed explanation of normal physiology and a re-education concerning the optimum defecatory patterns. ${ }^{139}$ The supportive relationship with the therapist undoubtedly contributes to the overall positive effect. Interestingly, this report found no relation between the observed benefit and any demonstrable physiological defect. There are few randomised studies, but using a mixture of eight weeks of progressive relaxation therapy, biofeedback, and coping strategies, two small $(n=19$ and $n=21)$ trials showed a global improvement in symptoms compared with symptom monitoring controls. ${ }^{140} 141$ The improvement in symptoms over pretreatment levels was maintained at two years but no placebo group was available for comparison at this time. ${ }^{142}$ Importantly, a subsequent placebo controlled study of 60 patients showed no specific benefit of relaxation, thermal biofeedback, and cognitive therapy compared with an attention-placebo control (pseudo-meditation and EEG alpha suppression biofeedback). This strongly suggests that the benefit was non-specific and due to attention, ${ }^{134}$ a conclusion supported in a recent review of the literature. ${ }^{143}$ 
7.9 HYPNOTHERAPY

Hypnosis is used to induce a state of relaxation and to alter the underlying abnormalities of gut motility and/or sensation in the presence of the therapist, with the ultimate aim of enabling patients to control symptoms on their own. Success depends very much on the enthusiasm of the therapist. An early controlled trial of hypnotherapy involving 30 patients with refractory IBS treated over a three month period showed that patients treated with hypnotherapy improved significantly compared with a group of patients receiving a similar contact time spent discussing emotional problems and stress. ${ }^{144}$ A follow up study confirmed long term efficacy and suggested that treatment was more likely to be successful with younger patients and those without serious psychopathology. ${ }^{145}$ A further study from another centre had a lower improvement rate $(61 \%)$ but found group therapy equally as effective as individual therapy. ${ }^{146}$ Unfortunately, hypnosis is time consuming and expensive to provide but is cost effective in severe refractory cases.

\subsection{COGNITIVE BEHAVIOURAL THERAPY}

Cognitive behavioural therapy (CBT) is based on the assumption that IBS in some patients is a behavioural disease generated by responses to life events. CBT involves helping the patient to recognise maladaptive patterns of thinking and behaviour. It encourages them to change how they interpret bodily sensations and changes in visceral function by seeing them, not so much as symptoms of disease which need to be treated, but more as expressions of anxiety that are associated with particular life events. Treatment is essentially an exercise in identification and solving of problems which facilitates a greater sense of control and autonomy in the patient. CBT insists that the patient takes some responsibility for the illness and helps him/her find a more healthy way of dealing with the underlying problem. While widely used in other fields, there have been few controlled studies of efficacy in IBS. Two small studies $(\mathrm{n}=20$ and $\mathrm{n}=34)$ from the same group compared cognitive therapy with untreated controls. Both studies used eight weeks of therapy with symptom monitoring visits as placebo controls. Both found a significant reduction in abdominal pain, diarrhoea, constipation, belching, and nausea for up to three months. Sixty six per cent had a generalised anxiety disorder and there was little response to placebo. ${ }^{147} 148$

\subsection{DYNAMIC PSYCHOTHERAPY}

Analytical psychotherapy attempts to provide the patient with an insight into why particular symptoms have developed and what they might mean/represent in the light of changes in key relationships. There is an implicit assumption that this insight will cause long lasting changes in attitude and behaviour. Symptoms often seem to stem from significant life changes (often a loss of a relationship) set against the background of a fragile personality who has difficulty coping with separation. The patient works through his or her interpersonal difficul-

\section{Recommendations}

- Positive diagnosis, explanation of symptoms, their cause, and their relationship to physical, dietary, or psychological factors together with a supportive understanding relationship should be the mainstay of management. (Recommendation grade C.)

- Those with anxiety but without psychiatric disease who do not respond satisfactorily to the above may benefit from relaxation therapy. (Recommendation grade B.)

- Those patients with prominent psychiatric morbidity may respond to psychotherapy or cognitive behavioural therapy or require conventional psychiatric treatment, while those with less psychopathology may respond well to hypnotherapy. (Recommendation grade B.)

ties through the safe and contained relationship with the therapist. There is undoubtedly an important placebo (non-specific) effect, which the therapist seeks to exploit.

There are only three reported trials of dynamic psychotherapy and relaxation in addition to standard medical therapy. These showed long term improvement in about two thirds of patients, particularly in scores of abdominal pain and altered bowel habit compared with medical treatment alone. ${ }^{149-151}$ The patients had either been symptomatic for a year $^{151}$ or suffered from chronic symptoms unresponsive to conventional treatment. ${ }^{149} 150$ Two publications probably referred to the same patients. ${ }^{149} 150$ The treatment protocols included long and frequent appointments (45 minutes to four hours) and there was no attempt to control for this. On subgroup analysis, females and patients with overt psychiatric symptoms or pain precipitated by stress did best.

\subsection{PSYCHIATRY}

Not infrequently a careful history reveals important psychiatric illnesses, particularly depression and anxiety, which may with time come to overshadow the gut symptoms. Such illnesses need to be treated on their own merits and psychiatric referral is then appropriate.

\subsection{Pharmacological treatments}

Current pharmacological treatments have limited value. Specific benefit is only seen in a limited proportion, and although the immediate placebo response is high, this wears off with time, causing repeated consultations. Drugs may be counterproductive in patients with major psychological problems as their prescription may reinforce abnormal illness behaviour and prevent patients dealing effectively with underlying psychological problems. However, for those patients who require therapy for specific symptoms, the following treatments have evidence to support them. 


\section{Recommendations}

- Various antispasmodics can be given to reduce pain, those with an anticholinergic action appearing to be slightly more effective. (Recommendation grade A.)

- Tricyclic antidepressants can be beneficial for pain, initially at a low dose, but occasionally higher doses may be required. They are best avoided if constipation is a major feature. (Recommendation grade A.)

8.1 ABDOMINAL PAIN

8.1.1 Antispasmodics

The commonest drugs prescribed for abdominal pain are the so-called antispasmodics which relax smooth muscle. Some, such as dicyclomine and hyoscine, are anticholinergic whereas others (mebeverine and alverine citrate) have a more direct inhibitory effect on intestinal smooth muscle. Meta-analysis of 26 double blind trials found a significant additional benefit for drug over placebo (average improvement $64 \%$ v $45 \%$ on placebo) but individual drug meta-analysis failed to show significant reduction in pain for the commonest drug used in the UK, mebeverine, although it showed global benefit. ${ }^{152}$ The most significant improvement in pain was found with the anticholinergic cimetropium bromide (which is not available in the UK), and dicyclomine bromide, but the common side effect of dry mouth may have unblinded the randomised studies. ${ }^{131} 153-162$

\subsubsection{Antidepressants}

These are currently the most effective drugs for treating IBS. As well as treating underlying depression they also modify gut motility and alter visceral nerve responses. Thus imipramine normalises the rapid small bowel transit seen in diarrhoea predominant IBS while another antidepressant, paroxetine (a selective serotonin reuptake inhibitor) accelerates small bowel transit, ${ }^{163}$ both of these effects being seen long before any effect on mood. Antidepressant therapies have been shown in several large randomised controlled trials to have significant benefit in the treatment of pain. Both low $(50 \mathrm{mg})$ and high $(150 \mathrm{mg})$ daily doses of tricyclic antidepressants (trimipramine and amitriptyline) have been used, nocturnal dosing producing the best response. Depression scores fell even with the lower dose. Constipation was the most significant side effect, ${ }^{164-167}$ a feature which is less problematic with the newer selective serotonin reuptake inhibitors.

\subsubsection{5-HT receptor antagonists/agonists}

A substantial number of new 5-HT antagonists/agonists are currently undergoing clinical trials. Early reports indicate that $5-\mathrm{HT}_{4}$ agonists improve constipation while $5-\mathrm{HT}_{3}$ antagonists reduce diarrhoea but their precise role in therapy is as yet unclear.

\section{Recommendations}

- Patients with urgency and diarrhoea can be successfully treated with loperamide at doses of 4-12 mg daily. Codeine is a reasonable alternative but more likely to cause unwanted sedation. (Recommendation grade A.)

- A small number of patients with diarrhoea predominant IBS have bile salt malabsorption and may respond to cholestyramine. (Recommendation grade B.)

\subsection{DIARRHOEA}

\subsubsection{Loperamide}

This slows small and large intestinal transit and reduces stool frequency and urgency in patients with IBS at doses of 4-12 mg daily. Divided doses as well as a single $4 \mathrm{mg}$ dose at night have been shown to be effective. ${ }^{75} 168$ Many patients learn to use loperamide prophylactically when they feel diarrhoea is likely to be a problem (for example, before going out).

\subsubsection{Codeine}

At doses of 15-30 mg, 1-3 times daily, codeine is also effective in functional diarrhoea but is more likely to cause sedation and drug dependency. ${ }^{169}$

\subsubsection{Cholestyramine}

This bile salt binding resin is effective in treating bile salt induced diarrhoea seen following terminal ileal resection. About $10 \%$ of diarrhoea predominant IBS patients show evidence of bile salt malabsorption. ${ }^{124}$ Successful response to cholestyramine depends on the percentage retention of a radiolabelled bile acid probe $\left({ }^{75} \mathrm{SeHCAT}\right)$ being $<5 \%$. Less severe malabsorption is common but such patients do not respond well to cholestyramine and it is likely that such minor degrees of malabsorption are simply due to fast small bowel transit. ${ }^{170}$ The natural history of such patients is variable during follow up; about $50 \%$ remit while about one in 10 are found to have IBD. ${ }^{171}$ However, tolerability of cholestyramine is poor and many patients prefer loperamide which is equally effective.

\subsection{CONSTIPATION}

Increasing intake of a range of different dietary "fibres" including those from cereals, fruits, and vegetables have been shown to increase stool weight and accelerate gut transit. However, this involves changing habits of a lifetime and most patients benefit from discussion with a dietitian. Fibre supplements may be helpful initially to demonstrate the benefit of increased fibre but their effectiveness may decline with time owing to substrate induction of increased fermentation by colonic flora. Wheat bran is the best known and probably the most effective fibre supplement to increase stool weight and decrease whole gut transit time. It has been effective in most studies at doses of 10-30 g daily but there were high drop out rates. ${ }^{172} \mathrm{~A}$ proportion of patients are intolerant of bran 
Recommendations

- Patients with IBS and constipation should be given a trial of increased intake of dietary fibre. (Recommendation grade C.)

- Those failing to respond or who are intolerant of increased dietary fibre could be tried with a fibre supplement. Ispaghula husk is a useful alternative to wheat bran, particularly in patients with pain, bloating, and excessive wind. (Recommendation grade $\mathrm{B}$.)

and experience worsening of symptoms, notably wind, distension, and pain. ${ }^{74}{ }^{172-176}$ Ispaghula husk similarly improves stool frequency at doses of 7-10.8 g daily with less of the adverse effects associated with wheat bran. ${ }^{132} 161177178$

\subsection{OTHER DRUGS}

Cisapride is a prokinetic agent with proven effectiveness in delayed gastric emptying, especially in patients with diabetes mellitus. In IBS it has been used in predominantly constipated patients with contradictory results ${ }^{179} 180$ and its use in this situation cannot currently be recommended.

Trials with peppermint oil have been too small to be convincing and the results were contradictory. ${ }^{181-183}$ Its use cannot be specifically recommended unless larger studies support its use.

The role of sodium cromoglycate is controversial as there is no good evidence that symptoms in IBS are caused by type I hypersensitivity reactions or that there is an increased incidence of IBS in atopic patients. However, this drug has been used with and without exclusion diets in the treatment of patients with reported food intolerance and higher success rates have been found in patients with positive skin prick reactions to food extracts. ${ }^{103} 104$ These studies were neither blinded nor adequately controlled and the principle remains unsubstantiated.

\subsection{Cost effectiveness}

The current cost of managing patients with FGD is difficult to estimate as its main determinant is the disruption to patients' lives which it is difficult to quantify. Costs may also be generated in other specialities. IBS patients have more non-GI complaints, which also result in consultations. ${ }^{35}$ They are over represented in gynaecology outpatients ${ }^{39}$ where they are less likely to achieve a final diagnosis ${ }^{40}$ and three times as likely to undergo a hysterectomy. ${ }^{41}$ They are also more likely to undergo appendicectomy or ovarian surgery. ${ }^{42}$ These are not included in most estimates of health care costs. A recent review of costs directly attributable to IBS based on epidemiology, consulting behaviour, market research of GP prescribing, and survey of hospital consultant practice estimated a cost of $£ 90$ per consulting sufferer per year. ${ }^{184}$ This was less than half a similar estimate made in the USA which estimated total healthcare costs of US $\$ 313$ per

\section{Recommendations}

- Although many other drugs are used, none has sufficient supporting evidence to be recommended. (Recommendation grade C.)

person with IBS, excluding prescription charges. ${ }^{185}$ This may reflect a more complete collation of costs in the US study that had access to a very comprehensive community based costing system. Although individually small, the large number of consultations (approximately 240000 new cases per year in the $\mathrm{UK}^{93}$ ) mean that total costs to the NHS are substantial ( $£ 22$ million).

Drugs for FGD are generally cheap at present but reinforcing abnormal illness behaviour, leading in turn to increased consultations, may increase costs in the future. Formal psychological treatment is expensive but may yet prove cost effective if it prevents unnecessary gastroenterological consultations and procedures. By addressing underlying psychopathological problems, it may also prevent attendance with non-GI functional complaints.

\section{Management guide for IBS: summary}

MAKE A POSITIVE DIAGNOSIS

- Those $<45$ years, meeting three or more criteria without sinister symptoms can be given a confident diagnosis without the need for extensive tests.

LISTEN TO THE PATIENT

- Address the patient's concerns, discuss and identify patient's beliefs; a diary may be helpful.

\section{EXPLANATION AND REASSURANCE}

- Benign prognosis, relapsing/remitting course.

- Idea of brain-gut interaction.

- Stress may aggravate symptoms or exacerbate worry about condition and impair coping abilities.

- Sensitive? hyperactive gut.

- Some precipitated by bacterial gastroenteritis.

HEALTHY LIFESTYLE ADVICE

- Balanced diet with adequate fibre intake, exercise, and regular time for defecation.

DIETARY ADVICE

- Establish habitual fibre intake.

- Explain in simple terms how fibre stimulates bowel.

- Increase or decrease fibre intake for constipation or diarrhoea, respectively.

- Identify excessive lactose, fructose, sorbitol, caffeine, or alcohol intake in those with diarrhoea.

- Trial of lactose/fructose/alcohol exclusion if appropriate.

- Reassure that true allergy is rare but food intolerance (for example bran) is common. 
- Expert dietetic advice for selected patients on excessively restrictive diet or when food intolerance is suspected.

PSYCHOLOGICAL CONSIDERATIONS

- Identify features of psychological disorders.

- Disorders of sleep and mood.

- Previous psychiatric disease/history of current or past physical/sexual abuse.

- Poor social support/adverse social factors (separation, bereavement).

- Identify somatisation: multiple somatic complaints, frequent visits to doctor.

PSYCHOLOGICAL TREATMENT

- Initially explanation and reassurance.

- Trial of simple relaxation therapy possibly using audiotapes.

- Other therapies (limited availability). Biofeedback, especially for disordered defecation. Hypnotherapy: exclude those with overt psychiatric disease. Cognitive behavioural therapy, dynamic psychotherapy.

- Psychiatric referral for serious psychiatric disease.

PHARMACOLOGICAL APPROACH

- Current treatments of limited value

- Identify main complaint. Specific symptoms may respond in a limited proportion of patients as follows:

\section{Abdominal pain}

- Antispasmodics: anticholinergic agents (dicyclomine)

- Antidepressants: tricyclics (amitriptyline/ trimipramine) especially where insomnia prominent but may aggravate constipation. Selective serotonin reuptake inhibitors still under evaluation.

Diarrhoea

- Loperamide 4-12 mg daily either regularly or prophylactically (e.g. before going out).

- Codeine 30-60 mg, 1-3 times daily can be tried but CNS effects often unacceptable.

- Cholestyramine may specifically benefit a small number but often less well tolerated than loperamide.

Constipation

- Increase dietary fibre (bran); if symptoms exacerbated try ispaghula/psyllium.

Bloating

- Try reducing intake of fibre/lactose/ fructose as relevant.

\subsection{Appendix}

MEMBERS OF WORKING PARTY

Jacqueline Boorman, BSc, SRD, Gastroenterology Dietitian, Brewery Cottage, Letchworth, Herts SG6 1DG, UK; Paul Cann MD, FRCP, consultant physician, Cleveland General Hospital, Middlesborough, Cleveland, UK; Alastair Forbes, BSc, MD, FRCP (cochairman), consultant physician, St Mark's Hospital, Northwick Park, UK; Jennifer Gomborone, MSc, PhD, clinical psychologist/ research fellow in gastroenterology, Digestive Diseases Research Centre, St Bartholomew's
Hospital, London, UK; Ken Heaton, MD, FRCP, reader in medicine and consultant physician, Department of Medicine, University of Bristol, Bristol, UK; Pali Hungin, MD, FRCGP, general practioner, Centre for Health Studies, University of Durham, Durham, UK; Devinder Kumar, MD, FRCS, Consultant Surgeon, St George's Hospital, Tooting, London, UK; Gerald Libby, FRCPsych, consultant psychiatrist, Department of Gastroenterology and Psychological Medicine, St Bartholomew's Hospital, London, UK; Robin Spiller, MSc, $\mathrm{MD}$, FRCP (co-chairman), reader in gastroenterology, Division of Gastroenterology, University Hospital, Queen's Medical Centre, Nottingham, UK; Professor Nicholas Read, MD, FRCP, Department of Human Physiology and Nutrition, University of Sheffield, Northern General Hospital, Sheffield, UK; David Silk, MD, FRCP, consultant physician, Department of Gastroenterology and Nutrition, Central Middlesex Hospital, London, UK; Peter Whorwell, MD, FRCP, senior lecturer, Department of Medicine, Withington Hospital, University Hospital of South Manchester, UK.

Conflict of interest. P Hungin has served on advisory boards for GlaxoWellcome and Novartis in relation to irritable bowel syndrome. A Forbes has acted as a paid consultant to GlaxoWellcome in respect of their work on irritable bowel syndrome, and previously contributed to their trials on alosereon. $\mathrm{He}$ has also been involved in trials on irritable bowel syndrome sponsored by Pfizer.

\subsection{References}

1 Moriarty KJ, Dawson AM. Functional abdominal pain: further evidence that the whole gut is affected. $B M \mathcal{F}$ 1982;284:1670-2.

2 Trimble KC, Farouk R, Pryde A, et al. Heightened visceral sensation in functional gastrointestinal disease is not site-specific: evidence for a generalized disorder of gut sensitivity. Dig Dis Sci 1995;40:1607-13.

3 Agreus L, Svardsudd K, Nyren O, et al. Irritable bowel syndrome and dyspepsia in the general population: Overlap and lack of stability over time. Gastroenterology 1995;109: and lack

4 Corney RH, Stanton R. Physical symptom severity, psychoogical and social dysfunction in a series of outpatients with irritable bowel syndrome. F Psychosom Res 1990;34:483-91.

5 Drossman DA, Li Z, Andruzzi E, et al. US householder survey of functional gastrointestinal disorders. Prevalence, sociodemography, and health impact. Dig Dis Sci 1993;38: 1569-80.

6 Hahn BA, Kirchdoerfer LJ, Fullerton S, et al. Patientperceived severity of irritable bowel syndrome in relation to symptoms, health resource utilization and quality of life. Aliment Pharmacol Ther 1997;11:553-9.

7 Manning AP, Thompson WG, Heaton KW, et al. Towards a positive diagnosis of the irritable bowel. BMf 1978;2:6534.

8 Taub E, Cuevas JL, Cook IIE, et al. Irritable bowel syndrome defined by factor analysis. Gender and race comparisons. Dig Dis Sci 1995;40:2647-55.

9 Drossman DA, Thompson WG, Talley NJ, et al. Identification of sub-groups of functional gastrointestinal disorders.
tions tion of sub-groups of functional gast

10 Thompson WG, Longstreth GF, Drossman DA, et al. Functional bowel disorders and functional abdominal pain. Gut 1999;45:II43-7.

11 Heaton KW, Radvan J, Cripps $\mathrm{H}$, et al. Defecation frequency and timing, and stool form in the general population: A prospective study. Gut 1992;33:818-24.

12 Talley NJ, O'Keefe EA, Zinsmeister AR, et al. Prevalence of gastrointestinal symptoms in the elderly: A populationbased study. Gastroenterology 1992;102:895-901.

13 Jones R, Lydeard S. Irritable bowel syndrome in the general population. BMF 1992;304:87-90.

14 Kay L, Jorgensen T, Jensen KH. The epidemiology of irritable bowel syndrome in a random population: Prevalence, incidence, natural history and risk factors. F Intern Med 1994;236:23-30

15 Heaton KW, O'Donnell LD, Braddon FM, et al. Symptoms of irritable bowel syndrome in a British urban community: Consulters and nonconsulters. Gastroenterology 1992;102: 1962-7. 
16 Schlemper R, Van der Werf SJ, Vandenbroucke JP, et al. Peptic ulcer, non-ulcer dyspepsia and irritable bowel
syndrome in the Netherlands and Japan. Scand f Gastroensyndrome in the Netherlan
terol Suppl 1993;28:33-41.

17 Zuckerman MJ, Guerra LG, Drossman DA, et al. Comparison of bowel patterns in hispanics and non-hispanic whites. Dig Dis Sci 1995;40:1763-9.

18 Olubuyide IO, Olawuyi F, Fasanmade AA. A study of irritable bowel syndrome diagnosed by Manning criteria in an African population. Dig Dis Sci 1995;40:983-5.

19 Danivat D, Tankeyoon M, Sriratanaban A. Prevalence of irritable bowel syndrome in a non-Western population. BMF 1988;296:1710-14.

20 Zuckerman MJ, Guerra LG, Drossman DA, et al. Health-care-seeking behaviors related to bowel complaints: Hispanics versus non-Hispanic whites. Dig Dis Sci Hispanics vers

21 Talley NJ, Zinsmeister AR, Van Dyke C, et al. Epidemiology of colonic symptoms and the irritable bowel syndrome. Gastroenterology 1991;101:927-34.

22 Longstreth GF, Wolde-Tsadik G. Irritable bowel-type symptoms in $\mathrm{HMO}$ examinees. Prevalence, demographics, and clinical correlates. Dig Dis Sci 1993;38:1581-9.

23 Drossman DA, Sandler RS, McKee DC, et al. Bowel patterns among subjects not seeking health care. Use of a questionnaire to identify a population with bowel dysfuncquestionnaire to identify a population
tion. Gastroenterology 1982;83:529-34.

24 Lembo T, Fullerton S, Diehl D, et al. Symptom duration in patients with irritable bowel syndrome. Am f Gastroenterol

25 Whitehead WE, Engel BT, Schuster MM. Irritable bowel syndrome. Physiological and psychological differences between diarrhea-predominant and constipationpredominant patients. Dig Dis Sci 1980;25:404-13.

26 Svedlund J, Sjodin I, Dotevall G, et al. Upper gastrointestinal and mental symptoms in the irritable bowel syndrome. Scand 7 Gastroenterol 1985;20:595-601.

27 Gomborone J, Dewsnap P, Libby G, et al. Abnormal illness attitudes in patients with irritable bowel syndrome. $\mathcal{F}$ Psychosom Res 1995;39:227-30.

28 Ford MJ, Miller PC, Eastwood J, et al. Life events, psychiatric illness and the irritable bowel syndrome. Gut 1987;28 $160-5$.

29 Whitehead WE, Bosmajian L, Zonderman AB, et al. Symptoms of psychologic distress associated with irritable bowel syndrome. Comparison of community and medical clinic samples. Gastroenterology 1988;95:709-14.

30 Smith RC, Greenbaum DS, Vancouver JB, et al. Psychosocial factors are associated with health care seeking rather than diagnosis in irritable bowel syndrome. Gastroenterology 1990;98:293-301.

31 Talley NJ, Phillips SF, Melton LJ, et al. Diagnostic value of the Manning criteria in irritable bowel syndrome. Gut the Manning

32 Delvaux M, Denis P, Allemand H. Sexual abuse is more frequently reported by IBS patients than by patients with organic digestive diseases or controls. Results of a multicentre inquiry. Eur $\mathcal{F}$ Gastroenterol Hepatol 1997;9: 345-52.

33 Talley NJ, Boyce PM, Jones M. Is the association between irritable bowel syndrome and abuse explained by neuroticism? Gut 1998;42:47-53.

34 Creed F, Craig T, Farmer R. Functional abdominal pain, psychiatric illness, and life events. Gut 1988;29:235-42.

35 Sandler RS, Drossman DA, Nathan HP, et al. Symptom complaints and health care seeking behavior in subjects
wtih bowel dysfunction. Gastroenterology $1984 ; 87: 314-18$.

36 Drossman DA, McKee DC, Sandler RS, et al. Psychosocial factors in the irritable bowel syndrome. A multivariate factors in the irritable bowel syndrome. A multivariate study of patients and nonpatients with
drome. Gastroenterology 1988;95:701-8.

37 Sandler RS, Drossman DA, Nathan HP, et al. Symptom complaints and health care seeking behavior in subjects wtih bowel dysfunction. Gastroenterology 1984;87:314-18

38 Van Der Horst HE, Van Dulmen AM. Do patients with irritable bowel syndrome in primary care really differ from outpatients $669-74$.

39 Prior A, Wilson K, Whorwell PJ, et al. Irritable bowel syndrome in the gynecological clinic. Survey of 798 new referrals. Dig Dis Sci 1989;34:1820-4.

40 Prior A, Whorwell PJ. Gynaecological consultation in patients with the irritable bowel syndrome. Gut 1989;30: 996-8.

41 Whitehead WE, Cheskin LJ, Heller BR, et al. Evidence for exacerbation of irritable bowel syndrome during menses. exacerbation of irritable bowel s
Gastroenterology 1990;98:1485-9.

42 Burns DG. The risk of abdominal surgery in irritable bowel syndrome. S Afr Med f 1986;70:91-5.

43 Whitehead WE, Winget C, Fedoravicius AS. Learned illness behavior in patients with irritable bowel syndrome and peptic ulcer. Dig Dis Sci 1982;27:202-8.

44 Gomborone JE, Dewsnap PA, Libby GW, et al. Selective affective biasing in recognition memory in the irritable bowel syndrome. Gut 1993;34:1230-3.

45 Gwee KA, Graham JC, McKendrick MW, et al. Psychometric scores and persistence of irritable bowel after infectious diarrhoea. Lancet 1996;347:150-3.

46 Greenson JK, Stern RA, Carpenter SL, et al. The clinical significance of focal active colitis. Hum Pathol 1997;28: 729-33.

47 Hotopf M, Carr S, Mayou R, et al. Why do children have chronic abdominal pain, and what happens to them when they grow up? Population base cohort study. BMF ;316:1196-200

48 Williams CL, Villar RG, Peterson JM, et al. Stress-induced changes in intestinal transit in the rat: A model for irritable bowel syndrome. Gastroenterology 1988;94:611-21.

49 Gorard DA, Gomborone JE, Libby GW, et al. Intestinal ransit in anxiety and depression (see comments). Gut 1996;39:551-5.

50 Valori RM, Kumar D, Wingate DL. Effects of different types of stress and of "prokinetic" drugs on the control of the fasting motor complex in humans. Gastroenterology 1986; 90:1890-900

51 Cann PA, Read NW, Cammack J, et al. Psychological stress and the passage of a standard meal through the stomach and small intestine in man. Gut 1983;24:236-40.

52 Fukudo S, Nomura T, Muranaka M, et al. Brain-gut response to stress and cholinergic stimulation in irritable bowel syndrome: A preliminary study. 7 Clin Gastroenterol 1993;17:133-41.

53 Narducci F, Snape WJJ, Battle WM, et al. Increased colonic motility during exposure to a stressful situation. Dig Dis Sci 1985;30:40-4

54 Narducci F, Snape WJJ, Battle WM. Increased colonic motility during exposure to a stressful situation. Dig Dis $\mathrm{Sci}$ 1985;30:40-4.

55 Lenz HJ, Raedler A, Greten H, et al. Stress-induced gastrointestinal secretory and motor responses in rats are mediated by endogenous corticotropin-releasing factor. Gastroenterology 1988;95:1510-17.

56 Martinez V, Rivier J, Wang L, et al. Central injection of a new corticotropin-releasing factor (CRF) antagonist, astressin, blocks CRF- and stress-related alterations of gastric and colonic motor function. 7 Pharmacol Exp Ther 1997;280:754-60.

57 Williams CL, Peterson JM, Villar RG, et al. Corticotropinreleasing factor directly mediates colonic responses to stress. Am 7 Physiol 1987;253:G582-6.

58 Fukudo S, Nomura T, Hongo M. Impact of corticotropinreleasing hormone on gastrointestinal motility and adrenocorticotropic hormone in normal controls and patients with irritable bowel syndrome. Gut 1998;42:845-9.

59 Narducci F, Snape WJJ, Battle WM. Increased colonic motility during exposure to a stressful situation. Dig $\mathrm{Dis} S \mathrm{Si}$ 1985;30:40-4

60 Bharucha AE, Camilleri M, Ford MJ, et al. Hyperventilation alters colonic motor and sensory function: Effects and mechanisms in humans. Gastroenterology 1996;111:368-77.

61 Lee CT, Chuang TY, Lu CL, et al. Abnormal vagal cholinergic function and psychological behaviors in irritable bowel syndrome patients: a hospital-based Oriental study. Dig Dis Sci 1998;43:1794-9.

62 Heitkemper M, Burr RL, Jarrett M, et al. Evidence for autonomic nervous system imbalance in women with irritable bowel syndrome. Dig Dis Sci 1999;43:2093-8.

63 Aggarwal A, Cutts TF, Abell TL, et al. Predominant symptoms in irritable bowel syndrome correlate with specific autonomic nervous system abnormalities. Gastroenterology 1994;106:945-50.

64 Camilleri M, Fealey RD. Idiopathic autonomic denervation in eight patients presenting with functional gastrointestinal

5 Snape WJJ, Carlson GM, Cohen S. Colonic myoelectric activity in the irritable bowel syndrome. Gastroenterology 1976;70:326-30

66 Latimer P, Sarna S, Campbell D. Colonic motor and myoelectrical activity: A comparative study of normal subjects, psychoneurotic patients, and patients with irritable jects, psychoneurotic patients, and patients with irrital

67 Sarna S, Latimer P, Campbell D, et al. Effect of stress, meal and neostigmine on rectosigmoid electrical control activity (ECA) in normals and in irritable bowel syndrome patients. Dig Dis Sci 1982;27:582-91.

68 Bazzocchi G, Ellis J, Villanueva-Meyer J, et al. Postprandial colonic transit and motor activity in chronic constipation. Gastroenterology 1990;98:686-93.

69 Rogers J, Henry MM, Misiewicz JJ. Increased segmental activity and intraluminal pressures in the sigmoid colon of patients with the irritable bowel syndrome. Gut 1989;30: 634-41

70 Welgan P, Meshkinpour H, Beeler M. Effect of anger on colon motor and myoelectric activity in irritable bowel syndrome. Gastroenterology 1988;94:1150-6.

71 Welgan P, Meshkinpour H, Hoehler F. The effect of stress on colon motor and electrical activity in irritable bowel syndrome. Psychosom Med 1985;47:139-49.

72 Cann PA, Read NW, Brown C. Irritable bowel syndrome: Relationship of disorders in the transit of a single solid meal to symptom patterns. Gut 1983;24:405-11.

73 Arffman S, Andersen JR, Hegnhoj J. The effect of coarse wheat bran in the irritable bowel syndrome. A double-blin cross-over study. Scand $\mathcal{F}$ Gastroenterol 1985;20:295-8.

74 Cann PA, Read NW, Holdsworth CD. What is the benefit of coarse wheat bran in patients with irritable bowel syndrome? Gut 1984;25:168-73.

75 Cann PA, Read NW, Holdsworth CD, et al. Role of loperamide and placebo in management of irritable bowel syndrome (IBS). Dig Dis Sci 1984;29:239-47.

76 Vassallo M, Camilleri M, Phillips SF, et al. Transit through the proximal colon influences stool weight in the irritable bowel syndrome. Gastroenterology 1992;102:102-8.

77 Kellow JE, Phillips SF. Altered small bowel motility in irritable bowel syndrome is correlated with symptoms. Gastroenterology 1987;92:1885-93. 
78 Kellow JE, Phillips SF, Miller LJ, et al. Dysmotility of the small intestine in irritable bowel syndrome. Gut 1988.29: 1236-43.

79 Gorard DA, Libby GW, Farthing MG. Ambulatory small intestinal motility in 'diarrhoea' predominant irritable bowel syndrome. Gut 1994;35:203-10.

80 Ritchie J. Pain from distension of the pelvic colon by inflating a balloon in the irritable colon syndrome. Gut 1973;14 125-32.

81 Whitehead WE, Holtkotter B, Enck P, et al. Tolerance for rectosigmoid distention in irritable bowel syndrome. rectosigmoid distention in irrit
Gastroenterology 1990;98:1187-92.

82 Cullingford GL, Coffey JF, Carr-Locke DL. Irritable bowel syndrome: Can the patient's response to colonoscopy help with diagnosis? Digestion 1992;52:209-13.

83 Mertz H, Fullerton S, Naliboff B, et al. Symptoms and visceral perception in severe functional and organic dyspepsia. Gut 1998;42:814-22.

84 Trimble KC, Farouk R, Pryde A, et al. Heightened visceral sensation in functional gastrointestinal disease is not site-specific evidence for a generalized disorder of gut sensitivity. Dig Dis Sci 1995; 40:1607-13.

85 Cook IJ, Van Eeden A, Collins SM. Patients with irritable bowel syndrome have a greater pain tolerance than normal subjects. Gastroenterology 1987;93:727-33.

86 Naliboff BD, Munakata S, Fullerton S, et al. Evidence for two distinct perceptual alterations in irritable bowel syndrome. Gut 1997;41:505-12

87 Silverman DS, Munakata JA, Ennes H, et al. Regional cerebral activity in normal and pathological perception of visceral pain. Gastroenterology 1997;112:64-72.

88 Chaudhary NA, Truelove SC. The irritable colon syndrome. $Q \mathcal{F}$ Med 1962;123:307-22.

89 Harvey RF, Mauad EC, Brown AM. Prognosis in the irritable bowel syndrome: A 5 -year prospective study. Lancet 1987; 1:963-5.

90 Neal KR, Hebden J, Spiller R. Prevalence of gastrointestinal symptoms six months after bacterial gastroenteritis and risk factors for development of the irritable bowel syndrome: postal surve

91 McKendrick MW, Read NW. Irritable bowel syndromePost salmonella infection. F Infect 1994;29:1-3.

92 McMahon SB. Neuronal and behavioural consequences of chemical inflammation of rat urinary bladder. Agents Actions 1988;25:231-3.

93 Rodriguez LA, Ruigomez A. Increased risk of irritable bowel syndrome after bacterial gastroenteritis. BMF 1999;318: syndrom

94 Nanda R, James R, Smith H, et al. Food intolerance and the irritable bowel syndrome. Gut 1989;30:1099-104

95 Jones VA, Shorthouse M, Hunter JO. Food intolerance: A major factor in the pathogenesis of irritable bowe syndrome. Lancet 1982;2:1115-17.

96 King TS, Elia M, Hunter JO. Abnormal colonic fermentation in irritable bowel syndrome. Lancet 1998;352:1187-9.

97 Gudmand-Hoyer E, Riis P, Wulff HR. The significance of lactose malabsorption in the irritable colon syndrome. Scand $\mathcal{F}$ Gastroenterol 1973;8:273-8.

98 Suarez FL, Savaiano DA, Levitt MD. A comparison of symptoms after the consumption of milk or lactosesymptoms after the consumption of milk or lactose-
hydrolysed milk by people with self-reported severe lactose hydrolysed milk by people with self-reported
intolerance. $N$ Engl I Med 1995;333:1-4.

99 Farah DA, Calder I, Benson L, et al. Specific food intolerance: its place as a cause of gastrointestinal symptoms. Gut 1985;26:164-8.

100 Lessof MH, Wraith DG, Merrett TG, et al. Food allergy and intolerance in 100 patients- local and systemic effects. QfM 1980;XLIX:259-71.

101 Bengtsson U, Nilsson-Balknas U, Hanson LA, et al. Double blind, placebo controlled food reactions do not correlate to IgE allergy in the diagnosis of staple food correlate to IgE allergy in the diagnosis of staple fooc

102 Bengtsson U, Hanson LA, Ahlstedt S. Survey of gastrointestinal reactions to foods in adults in relation to atopy, presence of mucus in the stools, swelling of joints and arthralgia in patients with gastrointestinal reactions to foods. Clin Exp Allergy 1996;26:1387-94.

103 Stefanini GF, Saggioro A, Alvisi V, et al. Oral cromolyn sodium in comparison with elimination diet in the irritable bowel syndrome, diarrheic type. Multicenter study of 428 patients. Scand F Gastroenterol 1995;30:535-41.

104 Leri O, Tubili S, De Rosa FG, et al. Management of diarrhoeic type of irritable bowel syndrome with exclusion diet and disodium cromoglycate. Inflammopharmacology 1997; 5:153-8.

105 MacQueen G, Marshall J, Perdue M, et al. Pavlovian conditioning of rat mucosal mast cells to secrete rat mast cell ditioning of rat mucosal mast cells
protease II. Science 1989;243:83-5.

106 Santos J, Saperas C, Nogueiras M, et al. Release of mast cell mediators into the jejunum by cold pain stress in humans. Gastroenterology 1998;114:640-8.

107 Heaton KW, Ghosh S, Braddon FM. How bad are the symptoms and bowel dysfunction of patients with the irritable bowel syndrome? A prospective, controlled study with emphasis on stool form. Gut 1991;32:73-9.

108 Thompson WG. Gastrointestinal symptoms in the irritable bowel compared with peptic ulcer and inflammatory bowel disease. Gut 1984;25:1089-92.

109 Isgar B, Harman M, Kaye MD, et al. Symptoms of irritable bowel syndrome in ulcerative colitis in remission. Gut 1983;24:190-2.
110 Tolliver BA, Herrera JL, DiPalma JA. Evaluation of patients who meet clinical criteria for irritable bowel patients who meet clinical criteria for irritab
syndrome. Am $\mathcal{f}$ Gastroenterol 1994;89:176-8.

111 Poynard T, Couturier D, Frexinos J, et al. French experience of Manning's criteria in the irritable bowel syndrome. Eur $\mathcal{F}$ Gastroenterol Hepatol 1992;4:747-52.

112 Whorwell PJ, McCallum M, Creed FH, et al. Non-colonic features of irritable bowel syndrome. Gut 1986;27:37-40.

113 Maxton DG, Morris J, Whorwell PJ. More accurate diagnosis of irritable bowel syndrome by the use of 'non-colonic' symptomatology. Gut 1991;32:784-6.

114 Triadafilopoulos G, Simms RW, Goldenberg DL. Bowel dysfunction in fibromyalgia syndrome. Dig Dis Sci 1991;36: $59-64$.

115 Kruis W, Thieme C, Weinzierl M. A diagnostic score for the irritable bowel syndrome. Its value in the exclusion of organic disease. Gastroenterology 1984;87:1-7.

116 Frigerio G, Beretta A, Orsenigo G, et al. Irritable bowel syndrome: Still far from a positive diagnosis. Dig Dis Sci 1992;37:164-7.

117 MacIntosh DG, Thompson WG, Patel DG, et al. Is rectal biopsy necessary in irritable bowel syndrome? Am f Gastroenterol 1992;87:1407-9.

118 Luboinski J, Beaugerie L, Lamy P, et al. Most patients with functional diarrhea do not have minimal forms of lymphocytic or collagenous colitis. Gastroenterol Clin Biol 1996;20:838-43.

119 Hamm LR, Sorrells SC, Harding JP, et al. Utility of screening tests in irritable bowel syndrome. Gastroenterology

120 DiPalma JA, Narvaez RM. Prediction of lactose malabsorption in referral patients. Dig Dis Sci 1988;33:303-7.

121 Bytzer P, Stokholm M, Andersen I, et al. Prevalence of surreptitious laxative abuse in patients with diarrhoea of uncertain origin: a cost benefit analysis of a screening procedure. Gut 1989;30:1379-84.

122 Read NW, Krejs GJ, Read MG. Chronic diarrhea of unknown origin. Gastroenterology 1980;78:264-71.

123 Francis CY, Duffy JN, Whorwell PJ, et al. Does routine abdominal ultrasound enhance diagnostic accuracy in irriabdominal ultrasound enhance diagnostic accuracy in irri50 .

124 Merrick MV, Eastwood MA, Ford MJ. Is bile acid malabsorption underdiagnosed? An evaluation of accuracy of diagnosis by measurement of SeHCAT retention. BMf 1985;290:665-8.

125 Galatola G, Ferraris R, Pellerito R, et al. The prevalence of bile acid malabsorption in irritable bowel syndrome and the effect of cholestyramine: An uncontrolled open multicentre study. Eur F Gastroenterol Hepatol 1992;4:533-

126 Sciarretta G, Furno A, Morrone B, et al. Absence of histopathological changes of ileum and colon in functional chronic diarrhea associated with bile acid malabsorption, assessed by SeHCAT test: A prospective study. Am $\mathcal{f}$ Gastroenterol 1994;89:1058-61.

127 Van Tilburg AP, De Rooij FM, Van Blankenstein M, et al. Nat-dependent bile acid transport in the ileum: The balance between diarrhea and constipation. Gastroenterology 1990;98:25-32.

128 Svendsen JH, Munck LK, Andersen JR. Irritable bowel syndrome-prognosis and diagnostic safety. A 5-year follow-up study. Scand f Gastroenterol 1985;20:415-18.

129 Spiller RC. Problems and challenges in the design of IBS trials Part 1. A review of the experience from published trials. Am f Med 1999;107:915-75.

130 Klein KB. Controlled treatment trials in the irritable bowel syndrome: A critique. Gastroenterology 1988;95:232-41.

131 Dobrilla G, Imbimbo BP, Piazzi L, et al. Longterm treatment of irritable bowel syndrome with cimetropium bromide: A double blind placebo controlled clinical trial. Gut 1990;31:355-8.

132 Prior A, Whorwell PJ. Double blind study of ispaghula in irritable bowel syndrome. Gut 1987;28:1510-13.

33 Lucock MP, Morley S, White C, et al. Responses of consecutive patients to reassurance after gastroscopy:
results of self administered questionnaire survey. $B M \mathcal{F}$ 1997;315:572-5.

134 Blanchard EB, Schwarz SP, Suls JM, et al. Two controlled evaluations of multicomponent psychological treatment of irritable bowel syndrome. Behav Res Ther 1992; 30:175-89.

135 Symons P, Jones MP, Kellow JE. Symptom provocation in irritable bowel syndrome. Effects of differing doses of fructose-sorbitol. Scand f Gastroenterol 1992;27:940-4.

136 Parker TJ, Naylor SJ, Riordan AM, et al. Management of patients with food intolerance in irritable bowel syndrome: The development and use of an exclusion diet. 7 Hum Nutr Dietetics 1995;8:159-66.

137 Blanchard EB, Greene B, Scharff L, et al. Relaxation training as a treatment for irritable bowel syndrome. Biofeedback Self Regul 1993;18:125-32.

138 Voirol MW, Hipolito J. (Anthropo-analytical relaxation in irritable bowel syndrome: results 40 months later). Schweiz Med Wochenschr 1987;117:1117-19.

139 Chiotakakou-Faliakou E, Kamm MA, Roy AJ, et al. Biofeedback provides long-term benefit for patients with intractable, slow and normal transit constipation. Gut 1998;42:517-21.

140 Lynch PM, Zamble E. A controlled behavioral treatment study of irritable bowel syndrome. Behav Ther 1989;20: 23-23.

141 Neff DF, Blachard EB. A multi-component treatment for irritable bowel syndrome. Behav Ther 1987;18:70-83. 
142 Blanchard EB, Schwarz SP, Neff DF. Two-year follow-up of behavioral treatment of irritable bowel syndrome. Behav Ther 1988:19:67-73.

143 Loening-Baucke V. Biofeedback training in children with functional constipation. A critical review (see comments). Dig Dis Sci 1996;41:65-71.

144 Whorwell PJ, Prior A, Faragher EB. Controlled trial of hypnotherapy in the treatment of severe refractory irritable-bowel syndrome. Lancet 1984;2:1232-4

145 Whorwell PJ, Prior A, Colgan SM. Hypnotherapy in severe irritable bowel syndrome: Further experience. Gut 1987; 28:423-5.

146 Harvey RF, Gunary RM, Hinton RA, et al. Individual and group hypnotherapy in treatment of refractory irritable bowel syndrome. Lancet 1989;1:424-5.

147 Greene B, Blanchard EB. Cognitive therapy for irritable bowel syndrome. 7 Consult Clin Psychol 1994;62:576-82.

148 Payne A, Blanchard EB. Controlled comparison of cognitive therapy and self-help support groups in the treatment
of irritable bowel syndrome. F Consult Clin Psychol 1995;63: of irritable $779-86$.

149 Guthrie E, Creed F, Dawson D, et al. A controlled trial of psychological treatment for the irritable bowel syndrome.

150 Guthrie E. Brief psychotherapy with patients with refractory irritable bowel syndrome. $\mathrm{Br} \quad \mathcal{F}$ Psychother 1991;8:175-88.

151 Svedlund J, Sjodin I, Ottosson J, et al. Controlled study of psychotherapy in irritable bowel syndrome. Lancet 1983;2 589-92.

152 Poynard T, Naveau S, Mory B, et al. Meta-analysis of smooth muscle relaxants in the treatment of irritable bowe syndrome. Aliment Pharmacol Ther 1994;8:499-510.

153 Berthelot J, Centoneze M. Étude côntrolée en double aveugle Duspatalin (mébévérine) contre placebo, dans le

154 Kruis W, Weinzierl M, Schussler P, et al. Comparison of the therapeutic effect of wheat bran, mebeverine and the therapeutic effect of wheat bran, mebeverine and placebo in patients with
Digestion 1986;34:196-201.

155 Tasman-Jones C. Mebeverine in patients with the irritable colon syndrome: double blind study. $N Z$ Med 1973;77:232-5.

156 Prout BJ. The treatment of irritable bowel syndrome. Two doses of mebeverine compared. Practitioner 1983;227 $1607-8$

157 Centonze V, Imbimbo BP, Campanozzi F, et al. Ora cimetropium bromide, a new antimuscarinic drug, for long-term treatment of irritable bowel syndrome. $A m \mathcal{F}$ Gastroenterol 1988;83:1262-6.

158 Page JG, Dirnberger GM. Treatment of the irritable bowel syndrome with Bentyl (dicyclomine hydrochloride). $\mathcal{7}$ Clin Gastroenterol 1981;3:153-6.

159 Anonymous. Irritable colon syndrome treated with an antispasmodic drug. Practitioner 1976;217:276-80.

160 Matts SGF. An assessment of dicyclomine hydrochloride ("Merbentyl") in the irritable colon syndrome. Br f Clin Pract 1967;21:549-51.

161 Ritchie JA, Truelove SC. Treatment of irritable bowel syndrome with lorazepam, hyoscine butylbromide, and ispaghula husk. BMf 1979;1:376-8.

162 Tudor GJ. A general practice study to compare alverine citrate with mebeverine hydrochloride in the treatment of irritable bowel syndrome. Br F Clin Pract 1986;40:276-8.

163 Gorard DA, Libby GW, Farthing MJ. 5-Hydroxytryptamine and human small intestinal motility:
effect of inhibiting 5-hydroxytryptamine reuptake. Gut 1994;35:496-500

164 Myren J, Lovland B, Larssen S-E, et al. A double-blind study of the effect of trimipramine in patients with the irritable bowel syndrome. Scand $\mathcal{F}$ Gastroenterol 1984;19:83543.

165 Myren J, Groth H, Larssen SE. The effect of trimipramine in patients with the irritable bowel syndrome. A doubleblind study. Scand $\mathcal{F}$ Gastroenterol 1982;17:871-5.

166 Greenbaum DS. Preliminary report on antidepressant treatment of irritable bowel syndrome: Comments on com parison with anxiolytic therapy. Psychopharmacol Bull 1984 20:622-8.

167 Steinhart MJ, Wong PY, Zarr ML. Therapeutic usefulness of amitriptyline in spastic colon syndrome. Gastroenterology $1980 ; 78: 1270-2$.
168 Hovdenak N. Loperamide treatment of the irritable bowel syndrome. Scand F Gastroenterol Suppl 1987;22:81-4.

69 Palmer KR, Corbett CI, Holdsworth CD Double-blind cross-over study comparing loperamide, codeine and diphenoxylate in the treatment of chronic diarrhea. Gastroenterology 1980;79:1272-5.

170 Williams AK, Merrick MV, Eastwood MA. Idiopathic bile acid malabsorption-A review of clinical presentation, diagnosis, and response to treatment. Gut 1991;32:1004-6.

171 Luman W, Williams AK, Merrick MV, et al. Idiopathic bile acid malabsorption: long-term outcome. Eur $\mathcal{F}$ Gastroenterol Hepatol 1995; 7:641-5.

172 Gudmand-Hoyer E, Krag B, Kristensen E. A double-blind trial of the effect of wheat bran on symptoms of irritable bowel syndrome, Lancet 1976;1:270-2.

173 Manning AP, Heaton KW, Harvey RF. Wheat fibre and irritable bowel syndrome. A controlled trial Lancet 1977;2: 417-18.

174 Lucey MR, Clark ML, Lowndes J, et al. Is bran efficacious in irritable bowel syndrome? A double blind placebo controlled crossover study. Gut 1987;28:221-5.

175 Francis CY, Whorwell PJ. Bran and irritable bowel syndrome: Time for reappraisal. Lancet 1994;344:39-40.

176 Snook J, Shepherd HA. Bran supplementation in the treatment of irritable bowel syndrome. Aliment Pharmacol Ther 1994;8:511-14

177 Kumar A, Kumar N, Vij JC. Optimum dosage of ispaghula husk in patients with irritable bowel syndrome: Correlation of symptom relief with whole gut transit time and stool weight. Gut 1987;28:150-5.

178 Ritchie JA, Truelove SC. Comparison of various treatments for irritable bowel syndrome. BMF 1980;281:131719.

179 Schutze K, Brandstatter G, Dragosics B, et al. Doubleblind study of the effect of cisapride on constipation and abdominal discomfort as components of the irritable bowel syndrome. Aliment Pharmacol Ther 1997;11:387-94.

180 Van Outryve M, Milo R, Toussaint J, et al. "Prokinetic" treatment of constipation-predominant irritable bowel syndrome: A placebo-controlled study of cisapride. $7 \mathrm{Clin}$ Gastroenterol 1991;13:49-57.

181 Dew MJ, Evans BK, Rhodes J. Peppermint oil for the irritable bowel syndrome: A multicentre trial. Br f Clin Pract 1984;38:394.

182 Rees WW. Treating irritable bowel syndrome with peppermint oil. BMF 1979;2:835-6

183 Nash P, Gould SR, Barnardo DE. Peppermint oil does not relieve the pain of irritable bowel syndrome. Br f Clin Pract 1986;40:292-3.

184 Wells NEJ, Hahn BA, Whorwell PJ. Clinical economics review: irritable bowel syndrome. Aliment Pharmacol Ther 1997;11:1019-30.

185 Talley NJ, Gabriel SE, Harmsen WS, et al. Medical costs in community subjects with irritable bowel syndrome. Gastroenterology 1995;109:1736-41.

\subsection{Useful addresses}

IBS Bulletin, Free Post TK1409, Hampton Hill, Middlesex TW12 1BR, UK (freephone 0800-783-7327).

Penny Nunn, IBS Network, Northern General Hospital, Sheffield S5 7AU, UK (Tel: 0114261 1531).

INTERNET ADDRESSES

www.gastro.org/ibs.html-American Gastroenterology Association Public Section. www.nih.gov/medlineplus/organisations.htmlNational Institute of Health listing of organisations providing the public with information about health issues, including IBS and common bowel symptoms. 